\title{
Fenómenos de inestabilidad natural en macizos rocosos graníticos: laderas en jabre, campos de bolos y bolos irregulares de granito
}

\author{
Leandro R. Alejano(1), Ignacio Pérez-Rey ${ }^{(1,2)}$, Xián Estévez-Ventosa ${ }^{(1)}$, Mauro Muñiz-Menéndez ${ }^{(2)}$ y \\ Javier Arzúa ${ }^{(3)}$
}

(1) Departamento de Ingeniería de los Recursos Naturales y Medio Ambiente, Universidad de Vigo, España (2) Laboratorio de Geotecnia, CEDEX, Madrid, España

(3) Departamento de Ingeniería Metalúrgica y Minas, Universidad Católica del Norte, Antofagasta, Chile

\begin{abstract}
RESUMEN
En este artículo se presenta una revisión de los fenómenos de inestabilidad que se producen típicamente en laderas naturales en terrenos graníticos a partir de la experiencia acumulada por los autores, principalmente en el noroeste de la Península lbérica, que se caracteriza además por un clima oceánico muy húmedo con precipitaciones elevadas. Para ello, se presenta en primer lugar un breve repaso introductorio de aspectos geomorfológicos de los terrenos graníticos en el que se definen diferentes morfologías de laderas que pueden dar lugar a fenómenos de inestabilidad y que incluyen grandes bolos graníticos individuales y con formas típicamente elipsoidales, campos de bolos graníticos en zonas de escarpe y laderas de pendiente alta o media y, finalmente, laderas suaves de materiales graníticos descompuestos, denominados localmente jabres. En todos estos casos, la meteorización de los materiales graníticos juega un papel relevante, por lo que se explica brevemente como se van meteorizando y erosionando los macizos rocosos graníticos. Posteriormente y para cada una de estas tres casuísticas, se presenta un descripción típica de los fenómenos a estudiar y mecanismos de inestabilidad característicos a los que dan lugar y que habrá que analizar, se introducen las técnicas de caracterización adecuadas y se define el tipo de análisis de estabilidad más apropiado para los mismos. Finalmente, se presenta de forma breve un caso de estudio para cada fenomenología de inestabilidad.
\end{abstract}

Palabras clave: Deslizamiento, Desprendimiento, EstabilidadTaludes, Granito, Mecánica de Rocas.

\section{Natural instability phenomena in granitic rock masses: slopes in decomposed granite, boulder fields and irregular large granitic boulders}

\begin{abstract}
Based on the experience gathered by the authors, this article presents a review of the instability phenomena typically associated to natural slopes in granite terrains, focusing on conditions encountered in the northwest of the Iberian Peninsula, particularly in the region of Galicia, characterized by a very humid oceanic climate with high rainfall. Accordingly, a brief introductory review of geomorphological aspects of granitic terrains is presented, in which different slope morphologies are defined that can give rise to varied instability phenomena. Three types of potentially unstable slope environments are defined, namely high areas with large ellipsoidal shaped individual granite boulders, mid-slope regions formed by groups of average size granitic boulders and mild slopes formed by highly or completely decomposed granite, locally known as 'jabre'. In all these cases, the weathering of granite materials plays an important role, so we briefly explain how the granite rock masses are weathered and eventually eroded. Subsequently, and for each of these three cases, the authors present a typical description of the phenomena to be studied, the characteristic instability mechanisms observed and that need to be analyzed and the most appropriate characterization techniques to be applied. A case study concerning the stability analysis of a particular scenario of every type of instability phenomenon
\end{abstract}


is then presented.

Keywords: granite; landslides; rock-fall; rock mechanics; slope stability.

\section{ABRIDGED ENGLISH VERSION}

\section{Introduction}

This article presents a review of instability phenomena typically associated to natural slopes in granite terrains, focusing on conditions encountered in the northwest of the Iberian Peninsula. Three types of potentially unstable slope environments are defined, namely, high areas with large ellipsoidal shaped individual granite boulders, mid-slope regions formed by groups of medium-size granite boulders and, finally, mild slopes formed by highly or completely decomposed granite (Fig. 1). In all these cases, the weathering of the granite materials plays an important role.

Boulders are one of the most common and characteristic landforms of granite terrains and their origin can be encountered within the weathering sequence as described by Durgin (1977). These structures are formed through the mechanism of spheroidal weathering (Fig. 2), a chemical process that mainly affects uniform rocks masses with regular joint patterns, something typically occurring in granite rock masses, but also in other lithologies. Granite boulders are displayed with different shapes and sizes, from almost perfect spheres to ellipsoidal bodies, but also slender or irregular slabs (Fig. 3).

Probably, the best-known model on the origin and development of these formations is that proposed by Linton (1955), considering two stages in which sub-surface weathering acts first, giving way to a completely erosive process that removes saprolite whilst the boulders remain piled up in-situ (Figs. 4 and 5).

When the erosive processes continue until they reach the entire granite rock mass, a phenomenon typical of granite plains, the granite becomes completely decomposed, behaving like a soil-type material, which is referred to in the NW of the Iberian Peninsula as jabre (CDG: completely decomposed granite). One aspect that particularly defines the treatment of CDGs in geotechnical engineering is their typically heterogeneous spatial distribution and natural variability, a fact that may lead to completely different results obtained from boreholes carried out in a relatively small area (Fig. 6).

\section{Stability of slopes in decomposed granites}

Instabilities encountered in soils and poor-quality rock masses, such as completely decomposed granites, are typically associated to a kind of failure that occurs through the material, without following discontinuities but a line of minimum strength. It can be demonstrated that this line is a logarithmic spiral that can be fitted to a circle. The main theories are based on the fact that failure follows a circular surface, illustrated by a typical diagram as presented in Figure 7. These types of failure are usually triggered by strong precipitation - the reason why many of them may occur in rainy seasons (Fig. 8), but they can also be influenced by seismic movement or blasting.

One of the main aspects to correctly characterize decomposed granites is a good geotechnical characterization. Alejano \& Carranza-Torres (2011) proposed an empirically based approach that allows the estimation of the shear strength of this type of material in terms of Mohr-Coulomb cohesion and internal friction angle values (Fig. 9).

To illustrate this section, an analysis of an unstable natural slope in a granite valley is carried out. Some features of this case study can be found in Figures 10 and 11 and results from a numerical analysis for different scenarios are presented in Figure 12. The corresponding factors of safety are presented inTable 1.

\section{Stability and rockfall hazard in areas with active wea- thering processes}

As previously indicated, the presence of granite slopes with medium-size boulders spread on large areas is quite common. These boulders are usually displayed on fine-grain materials and even decomposed granite, a fact that complicates the stability analyses.

The stability of each boulder against sliding and toppling can be carried out through classical techniques (Hoek and Bray 1974) adapted to the particular conditions encountered. Rock-fall paths for these blocks can be computed by means of particle models implemented in different software (Rocscience 2017). Due to the difficulties presented by these methods, the previous approaches can be complemented by the application of empirical methodologies (Pierson et al 1990, Alejano et al. 2008, Mölk et al 2008).

This section is illustrated by a case study where a multi-approach assessment of rockfall hazard is carried out for a weathered granite rock slope affected by a forest fire in the NW of Spain (Perez-Rey et al. 2019). The area and block distribution are illustrated by Figures 13 and 14. The field work involved an in-situ characterization of those blocks and groups of blocks identified as potentially unstable (Fig. 15), assigning an annual probability value of destabilization for different hazard levels (Table 2). From a 3D point cloud obtained from the combination of LiDAR and aerial imagery from UAV, some lines of maximum slope were proposed (Fig. 16) to carry out different simulations with RocFall (Rocscience 2017) in order 
to quantify fall-paths and maximum kinetic energy of the rock-fall events (Fig. 17) allowing the analysis of potential impacts on buildings located below the slope (Table 3). It was recommended that to install a 3-m high dynamic barrier to protect these buildings by that would retain falling blocks according to the fall-path simulations and capable of assuming a 500 $k J$ maximum kinetic energy.

For guidance purposes, two empirical methodologies have also been applied to the present case study. Figure 18 shows the application of the RHRS method and Figure 19 represents some of the parameters for the $R^{3} S^{2}$ model (Mölk et al. 2008).

\section{Stability of isolated boulders}

Granite boulders are widespread geomorphological elements, particularly found in humid granite areas. Although they seldom represent a hazard for people or infrastructures, sometimes their location in steep or natural slopes, close to limit-equilibrium state, may jeopardize their stability and potentially affect people or infrastructures.

The stability analysis of a granitic boulder will require, on the one hand, a careful geometric characterization (dip angle and direction) and a geomechanical characterization of the discontinuity where the boulder rests. In addition, it is necessary to have a very accurate description of the geometry of boulder itself (center of gravity, volume...), something that only now can be achieved by means of recently developed methods for processing 3D point clouds obtained from the combination of advanced surveying techniques such as TLS and UAV aerial photogrammetry (Fig. 20).

Results from the previous processes will be necessary for the assessment of the limit-equilibrium analysis through the factor of safety, both against sliding and toppling mechanisms. The effect of rounding due to weathering processes on the stability of boulders is also a relevant factor influencing the stability, which can be assessed by updated formulations that can be illustrated with the help of abacuses such as that presented in Figure 21.

As an atypical example of the stability issues under scrutiny, the stability of a large granite boulder located on a $27^{\circ}$-dip slope in the SW of Galicia (NW Spain) (Fig. 22) has been researched. First, a geomechanical characterization of the discontinuity where the boulder rests were carried out and the main results are presented in Table 4. The geometry of the boulder and contact area were computed from a 3D point cloud obtained by combining a TLS and aerial imagery from an UAV, a process that is illustrated by Figure 23. The stability of the boulder was assessed both for static and worst seismic conditions, as considered by the Spanish seismic act (MFOM 2002). Factors of safety were in the range of 1.1 to 1.3 were derived, indicating that the stability of the boulder can be assured. In the event of an extraordinary earthquake of a similar magnitude to the so-called 'Lisbon Earthquake' its stability might be compromised.

\section{Conclusions}

This article presents a review of the instability phenomena prone to occur on natural granite slopes. One of the most relevant phenomenon that ultimately affects the stability of this type of rock masses is weathering, a mechanism from which the three main types of scenarios considered in this study originate: decomposed granite slopes, boulder fields and isolated irregular-shaped boulders.

For the first scenario, it is recommendable to resort to simple and economic characterization methods, as this type of material is highly variable both in its spatial distribution and behaviour. For the second, a combination of advanced topography techniques with semi-automated geostructural analysis on 3D point clouds allows us not only to obtain a realistic average block size for inputting into computational models but also to cover a large area of analysis in a relatively short time. To evaluate the stability of large irregular boulders, apart from classical geomechanical characterization techniques, it is critical to accurately determine the volume of the boulder, the contact area and the position of its centre of gravity, something that can be successfully achieved with the application of advanced topographic techniques.

\section{Introducción, contextualización y fenómenos de ines- tabilidad a estudiar}

En terrenos graníticos el paisaje es modelado por el efecto de la erosión sobre granitos u otras rocas plutónicas. Estos relieves y los elementos geomorfológicos asociados son producto de la meteorización, que deteriora y altera la roca física y químicamente, y de la erosión que elimina la parte alterada de la misma. Esta meteorización va asociada a tres factores que incluyen la composición mineralógica (las micas se oxidan con cierta facilidad, los feldespatos se caolinizan por hidrólisis más lentamente y el cuarzo resiste en forma de arenas); la textura, que tiene en cuenta el tamaño y forma de los minerales, su disposición y características y la fracturación que proporcionan vías preferenciales de meteorización.

La meteorización y erosión de sustratos graníticos da lugar a elementos característicos de los paisajes graníticos que se presentan en forma de elementos geomorfológicos mayores o megaformas que incluyen domos, crestones, lanchares, berrocales, pedrizas y arenizaciones. El domo es una masa de roca que presenta un aspecto redondeado formado por la meteorización a favor de diaclasas curvas, mientras que el crestón se forma a favor de un diaclasado vertical. Según aumenta la alteración de estos relieves, empiezan a formarse formas convexas tipo inselberg, denominadas en función de su aspecto en castellano berrocales, pedrizas, 
lanchares o bolos y, finalmente, la descomposición de los granitos dando lugar a los materiales denominados jabres o granitos descompuestos mediante procesos de arenización de la roca. Existen adicionalmente megaformas cóncavas y varias formas geomorfológicas menores, de pequeñas dimensiones como pilas, tafonis, etc... que quedan fueran del ámbito de estudio.

EI NW de la Península Ibérica, incluyendo las regiones de Galicia en España y Minho en Portugal, constituye una genuina representación de la geología granítica del Hercínico Europeo, con fenómenos de meteorización y erosión muy marcados durante el Mesozoico y fenómenos de reajuste de bloques de edad Cenozoica (que dieron lugar a la formación de las rías y los relieves montañosos suaves gallegos), lo que ha originado una variada representación de geoformas graníticas en las laderas de esta región. Esta variedad se asocia a la presencia de distintas rocas graníticas (granitos, granodioritas, sienitas...), variedad del medio geomórfico (marino, continental, fluvial...) y cierta variedad climática (de puramente oceánica a moderadamente continental) (Vidal-Romaní, 1989).

En este contexto y a partir de la experiencia de los autores en el ámbito de las laderas naturales en sustrato granítico se han identificado tres tipos característicos de fenómenos de inestabilidad (Figura 1). En primer lugar, se producen fenómenos de inestabilidad en taludes con pendientes suaves en materiales graníticos descompuestos o jabres que suelen presentar mecanismos de rotura típicos de suelos como la rotura circular. En segundo término, en laderas graníticas en macizos fracturados aparecen conjuntos de bloques de roca más o menos inmersos en una matriz de jabre, en los que se pueden producir desprendimientos, asociados a varios tipos potenciales de mecanismos de inestabilidad. Finalmente, aparecen en determinadas laderas graníticas bloques de granito individuales más o menos redondeados que pueden sufrir procesos de inestabilidad por vuelco o deslizamiento típicamente asociados a periodos de lluvias o a la ocurrencia de pequeños sismos. Las particularidades de cada uno de estos potenciales fenómenos de inestabilidad, hacen necesarias técnicas apropiadas derivadas de las disciplinas de la mecánica de suelos y rocas a su estudio, que, a su vez, presentan especificidades propias de la naturaleza de los materiales que forman las laderas.

En este artículo y tras esta introducción, se repasan los fenómenos de meteorización y erosión que dan lugar a cada uno de los contextos generadores de inestabilidad potencial. Después, se presentan para cada caso la descripción típica de los fenómenos de inestabilidad observados, las técnicas de caracterización adaptadas a los mismos, las metodologías de análisis apropiadas y un ejemplo de aplicación, de manera que el lector pueda familiarizarse con la fenomenología y método de análisis de estabilidad en cada uno de estos casos de problemas de estabilidad de taludes comunes en el ámbito de la geología granítica.

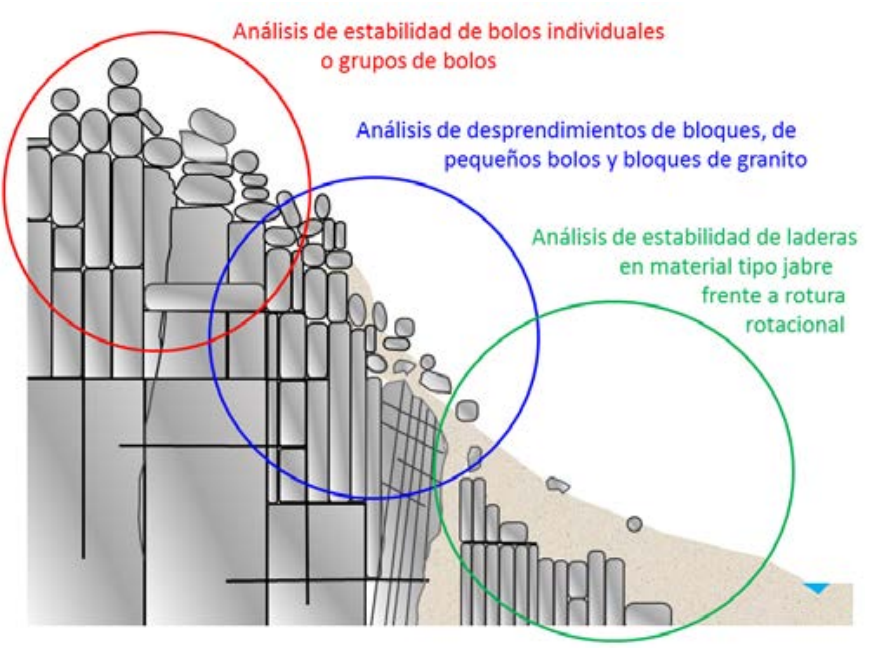

Figura 1. Esquema representativo de una típica ladera granítica e identificación de los fenómenos de inestabilidad que se podrían producir en cada una de las zonas.

Figure 1. Representative sketch of a typical granite slope and identification of the instability phenomena potentially occurring in each of the levels.

En lo que respecta a los jabres, se presenta un enfoque empírico que permite estimar la resistencia al corte de este tipo de materiales en términos de Mohr-Coulomb basada en ensayos semi-empíricos senciIlos y análisis retrospectivos de taludes inestables en granitos descompuestos, que se puede implementar posteriormente en técnicas clásicas de análisis de rotura rotacional o circular.

Para el caso de grupos de bloques sueltos en matriz tipo jabre, el planteamiento se basa en técnicas recientemente desarrolladas de análisis de desprendimientos, técnicas que han sido recientemente adaptadas para ser aplicadas en laderas graníticas formadas por bloques.

En cuanto a la estabilidad de grandes bolos sueltos con forma típicamente elipsoidal, los estudios tradicionales de taludes en roca (Hoek and Bray, 1974; WyIlie and Mah, 2004) desarrollaron metodologías para analizar la estabilidad de bloques con formas geométricas delimitadas por juntas planas preexistentes, como losas de roca, prismas, cuñas o columnas, bloques que tienden a formarse cuando se excavan taludes artificiales. La estabilidad frente al deslizamiento o vuelco de bloques individuales o conjuntos de bloques se puede cuantificar de acuerdo con estos enfoques tradicionales. Sin embargo, hasta ahora apenas se han desarrollado metodologías para estimar la estabilidad de bolos granito con formas irregulares de origen natural. Se introducen en este artículo algunas metodologías aplicables al estudio de la estabilidad de estos bolos, basadas en la caracterización geométrica avanzada.

En conclusión, se presenta una revisión de técnicas aplicables a la cuantificación de la estabilidad de laderas graníticas naturales basándose en la experiencia 
de múltiples casos en Galicia, aunque estas geomorfologías graníticas son comunes a amplias zonas de la tierra por lo que se citaran ejemplos similares en múltiples países típicamente en zonas de graníticas de áreas templadas del planeta (Portugal, Italia, Las islas británicas, Japón, EEUU en el hemisferio norte y Australia, Brasil, Zimbabue en el sur).

\section{Meteorización de macizos rocosos graníticos: forma- ción de bolos, campos de bolos y de jabres}

La meteorización es el proceso natural de fragmentación y descomposición in situ de las rocas en la superficie de laTierra, que se atribuye a la precipitación, la temperatura y la actividad biológica (Ollier, 1975). Desde un punto de vista geomorfológico, los efectos resultantes de los fenómenos meteorológicos adquieren una influencia particular en la génesis de paisajes rocosos asociados a distintos tipos de rocas y condiciones climáticas (Twidale y Vidal-Romaní, 2005). Los bolos graníticos son una de las formas de relieve más comunes y características de los terrenos graníticos. Su origen se puede encontrar dentro de la secuencia de meteorización típica de los macizos rocosos graníticos, tal y como lo describió Durgin (1977), en el que se pueden reconocer cuatro etapas típicas: roca sana, formación de bolos, granito descompuesto y saprolito. El desarrollo de estas estructuras está dominado por el mecanismo de la meteorización esferoidal, un proceso químico que afecta principalmente a rocas uniformes y con patrones de fisuración regulares como el granito y otras rocas ígneas granulares o el basalto (Fig. 2).

Hencher (2012), destaca la ocurrencia habitual de conjuntos de juntas ortogonales en rocas como el granito, que presentan dos familias de discontinuidades más o menos normales entre sí y a un plano de debilidad típico del granito denominado andar (Taboada et al., 2005). Estos conjuntos de juntas facilitan el flujo de agua a través del macizo rocoso, acelerando un proceso de intemperización diferencial.

El proceso de formación de bolos se desarrolla en dos fases: primero, la erosión superficial diferencial actúa sobre la masa de roca granítica, complementándose luego con eventos erosivos (viento, lluvia), que desarrollan la exhumación de elemento rocoso
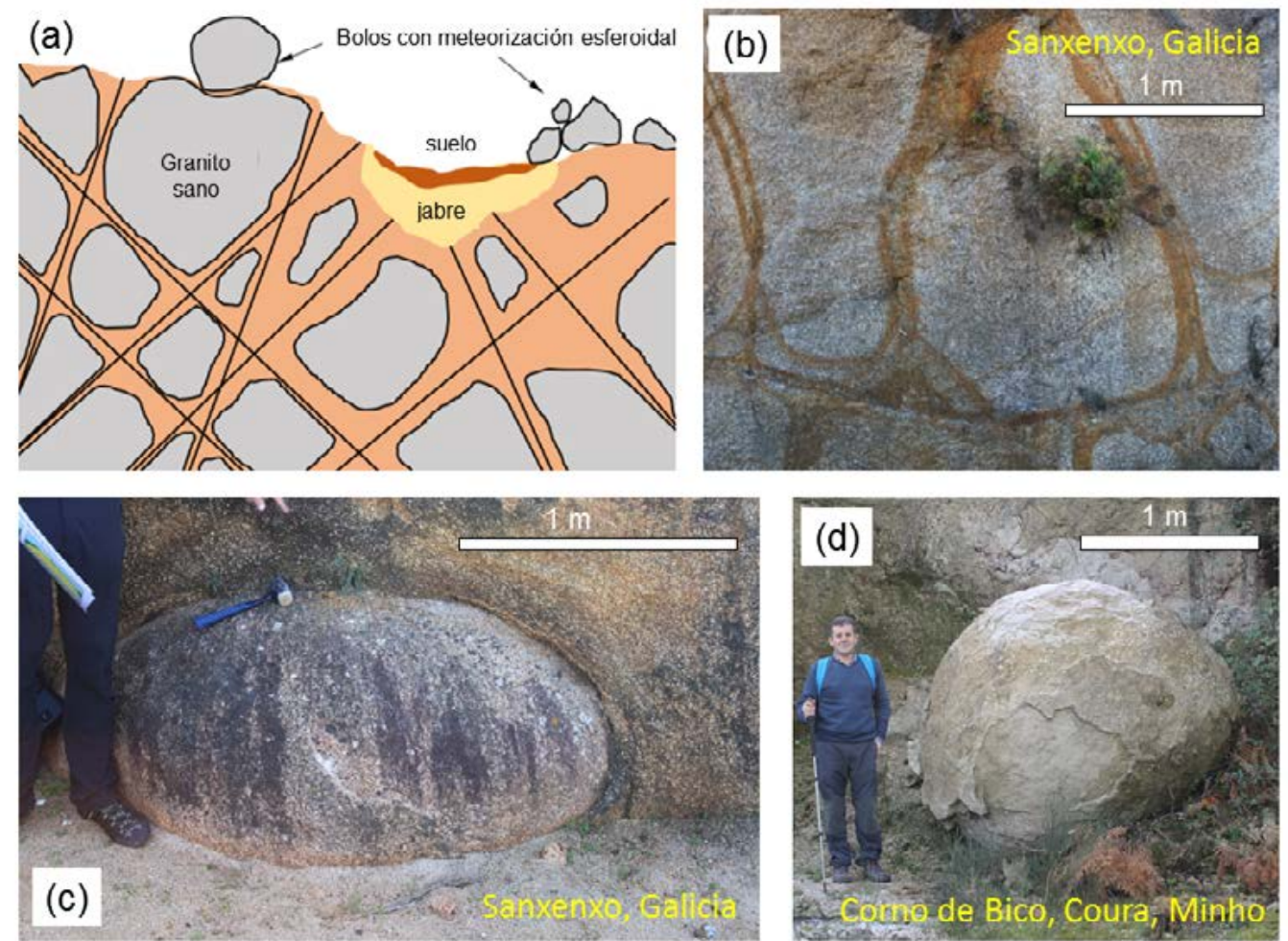

Figura 2. Esquema que muestra el proceso de formación de bolos graníticos (a) Bosquejo que muestra el desarrollo de cantos rodados como consecuencia del proceso de dos etapas por el mecanismo de meteorización esferoidal; (b) Meteorización esferoidal incipiente observada en un afloramiento granítico (Sanxenxo, Pontevedra, Galicia); (c) Bolo granítico sano en una matriz de granito meteorizado (Sanxenxo, Pontevedra, Galicia) y (d) Bolo granítico de unos 2 metros de diámetro recién salido de una matriz de jabre en el paraje de Corno do Bico (Paredes de Coura, Minho, Portugal).

Figure 2. Diagram illustrating the granite boulder formation process (a) Sketch showing the development of boulders as a consequence of the two-stage process of the spheroidal weathering (b) Incipient spheroidal weathering observed in a granite outcrop (Sanxenxo, Pontevedra, Galicia); (c) Sound granite boulder indented in a weathered granite matrix (Sanxenxo, Pontevedra, Galicia) and (d) Roughly $2 \mathrm{~m}$ diametre boulder recently released from a completely decomposed granite (CDG) matrix in the area of Corno do Bico (Paredes de Coura, Minho, Portugal). 
para formar un bolo (Fig. 2). La meteorización en el subsuelo altera principalmente las micas y los feldespatos para producir caolines, con la intervención de diferentes procesos químicos como la disolución, oxidación e hidrólisis (Linton, 1975; Ollier, 1971).

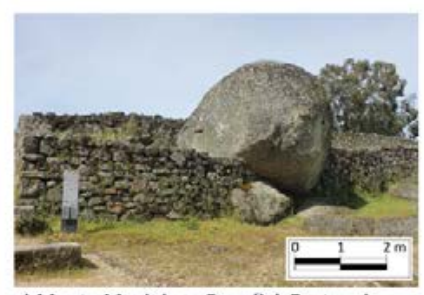

a) Monte Mozinhos, Penafiel, Portugal

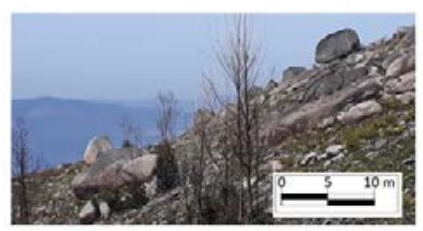

c) Redondela, Pontevedra, Galicia

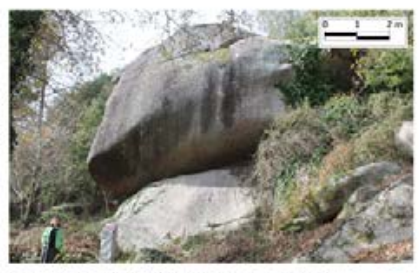

e) Ponteraeas, Pontevedra, Galicia

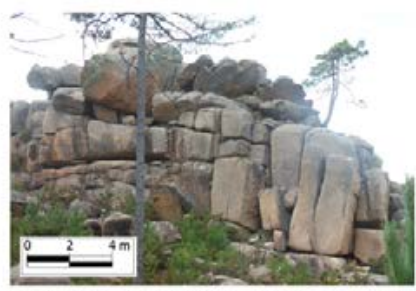

g) Monte Pindo, Carnota, A Coruña, Galicia

Figura 3. Diferentes ejemplos de rocas graníticas en el noroeste de la Península Ibérica: (a) Bolo granítico casi esférico en la entrada de un castro; (b) Bolo con forma de riñón que según la tradición podía balancearse, algo atribuido a una base cóncava; (c) Grandes bolos de granito en una ladera; (d) Varios bolos de grandes dimensiones en el sur de África, (e) Bolo de granito de grandes dimensiones; (f) Penedo grande, bolo de la menos 20.000 th de peso en la cima de un monte; (g) Bloques redondeados con forma de losa y (h) Roca muy grande (10.000 toneladas) en un pico de montaña semidescalzada. Ubicación de cada roca escrita debajo de cada imagen y escala aproximada reflejada. Todas las imágenes de los autores.

Figure 3. Different examples of granite rocks in the northwest of the Iberian Peninsula: (a) almost spherical granite boulder at the entrance of an Iron Age hill fort; (b) a kidney-shaped rock that, according to tradition, could swing (rocking stone), something attributed to a concave base; (c) large granite boulders on a mountain slope; (d) several large well-known granite boulders in Zimbabwe, (e) very large granite boulder; (f) 'Penedo Grande' a large boulder of at least 20,000 tons on the top of a hill; $(g)$ rounded corner slab-shaped blocks and (h) very large rock (10,000 tons) partially undercut on a mountain peak. Location of each rock written below each image and approximate scale reflected. All the images by the authors.
En términos generales, los bolos graníticos aparecen con diferentes formas geométricas, desde esferas casi perfectas hasta cuerpos elipsoidales y losas esbeltas, dependiendo del grado de intemperización al que fueron sometidos y a la variabilidad geométrica de las familias de juntas en los macizos rocosos de origen. Migón (2005) ha relacionado la presencia de grandes rocas aisladas o agrupadas con granitos de grano grueso, ricos en potasio y granitos post-Hercínicos, mientras que los campos de bolos, con tamaños menores de $2 \mathrm{~m}$ de longitud, se han asociado a áreas con granitos de grano fino mucho más antiguas. Ejemplos que muestran la diversidad geométrica y de tamaño de estos bolos principalmente del noroeste peninsular se ilustran en la Fig. 3. La geometría varía de casi esferas a elipsoides o paralelepípedos con esquinas redondeadas. Los pesos varían desde valores mínimos hasta 20,000 toneladas.

En lo que respecta a estructuras convexas formadas por bolos (tors) o colinas con laderas formadas por bolos de granito (inselbergs), el origen y desarrollo de estas formaciones ha sido analizado por varias teorías (Linton, 1955; Palmer y Neilson, 1962). Linton (1955) teorizó el modelo de dos fases según el cual el ambiente sub-superficial actúa primero, evolucionando a un proceso predominantemente erosivo mediante el cual se elimina el jabre mientras que las rocas permanecen in situ apiladas (Fig. 4 y 5).

a.

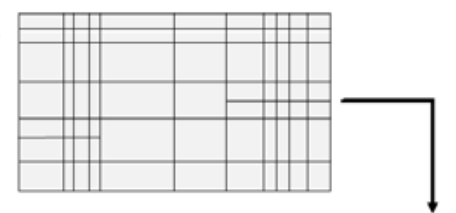

b.

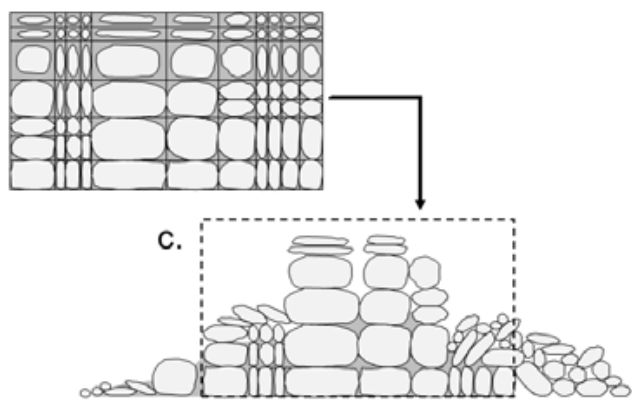

Figura 4. Boceto idealizado que representa la teoría en dos fases de la formación de tors o geoformas convexas formadas por múltiples bloques (Linton, 1955). (a). Masa de roca granítica original, que muestra la ortogonalidad de conjuntos de juntas; (b) Profunda penetración de la intemperie en la masa rocosa; (c). Etapa final con eliminación del saprolito, que muestra el llamado efecto de meteorización, compárese con las fotografías de las Figuras 1, 2, 3 y 5 .

Figure 4. Idealized sketch representing the two-stage theory of convex tor or multi-block geoform formation according to Linton (1955). (a). Original granite rock mass, showing the orthogonality of joint assemblies; (b) Weathering penetration through joints into the rock mass; (c). Final stage with the removal of the weathered and decomposed material. Compare to the photographs in Figures 1, 2, 3 and 5 . 

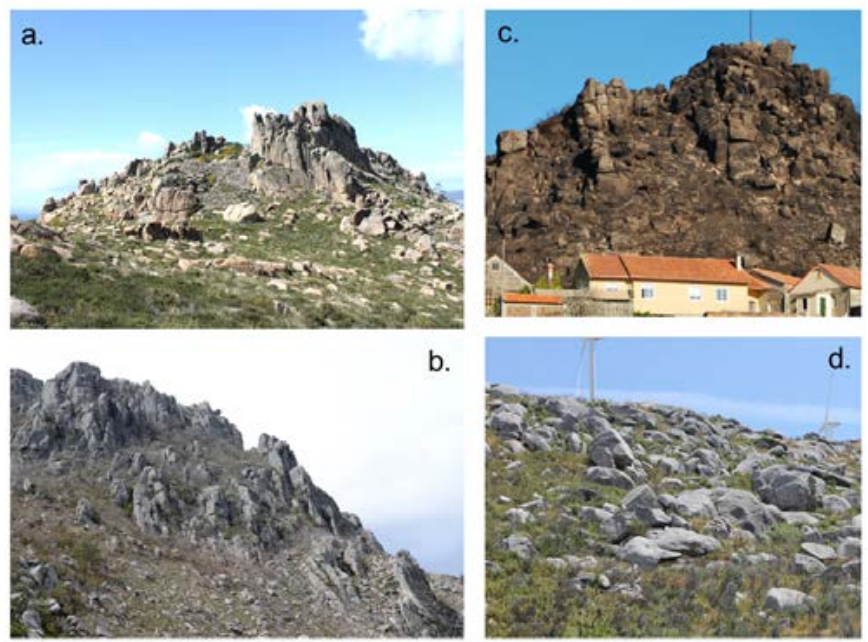

Figura 5. Diferentes formaciones graníticas con laderas formadas por bloques o campos de bolos en el noroeste de la Península Ibérica: (a). Monte Pindo (A Coruña, España); (b) Parque Nacional Peneda-Gerês (Região Norte, Portugal); (c) Área de estudio Monte do Castro (Pontevedra, España) y (d) ladera en la Serra de Arga junto a Viana do Castelo (Portugal).

Figure 5. Different granite formations with slopes formed by blocks or boulder fields in the northwest of the Iberian Peninsula: (a). Monte Pindo (A Coruña, Spain); (b) Peneda-Gerês National Park (Região Norte, Portugal); (c) Monte do Castro study area (Pontevedra, Spain) and (d) hillside in the Serra de Arga, nearby Viana do Castelo (Portugal).

Cuando la erosión continúa hasta alcanzar toda la masa granítica, fenómeno típico de llanuras graníticas, el granito se descompone completamente, comportándose como un suelo, llamado jabre en la zona. El jabre es por tanto un suelo o roquisuelo eluvial de granito, esto es, un material residual arcillo-limoso con arena de cuarzo, consistente en granito con todo su feldespato, e incluso parte de la mica, descompuestos. A veces conserva la estructura e incluso la apariencia del granito, y sólo excavándolo se aprecia su blandura (Jiménez-Salas et al., 1975). Debido al significativo porcentaje de granos de cuarzo, estos materiales suelen quedar clasificados como arenas (S) según la clasificación de Casagrande.

Desde el punto de vista de la meteorización y siguiendo la escala de Moye (1955) los jabres se encuadran en la gama de los granitos altamente descompuestos (grado de meteorización IV, cuando se pueden romper con la mano haciendo un ruido seco al golpear con el martillo), pasando por granitos completamente descompuestos (grado de meteorización $\mathrm{V}$, cuando aun a pesar de mantener la textura se desmigan fácilmente con la mano y penetra fácilmente la punta del martillo) hasta suelos residuales de granito (VI, cuando ya han perdido la textura). Esta clasificación es comúnmente utilizada en el ámbito de la literatura anglosajona donde los jabres son comúnmente denominados HDG (highly decomposed granite) o CDG (completely decomposed granite). (Sugawara et al., 2003).

Un aspecto que define el tratamiento de los jabres en geotecnia es su típicamente heterogénea distribución espacial y variabilidad natural, que hacen que los resulta- dos de un sondeo realizado en un punto, puedan diferir sustancialmente de los realizados en el entorno del mismo (GEO, 1988). Para ilustrar este aspecto se presenta en la Figura 6.a una imagen de un corte en una zona típica de jabre, marcándose sobre la misma el contacto entre el granito más sano y el jabre y representándose en la zona inferior el esquema geológico de la misma. Como muestra esta imagen el contacto entre jabre y granito suele ser muy irregular, siendo común la aparición de bolos de granito completamente inmersos en el jabre y viceversa.

Esta realidad se ilustra en la Figura 6.b donde aparece un talud de carretera excavado en terreno tipo jabre, en la que se muestra cómo a la izquierda de la foto el material tiene una consistencia rocosa mientras que a la derecha el material es más débil, observándose además variabilidades locales, puestas de manifiesto por la presencia de bolos de granito (material más resistente) y de fenómenos de inestabilidad local (pequeñas caídas).

a)
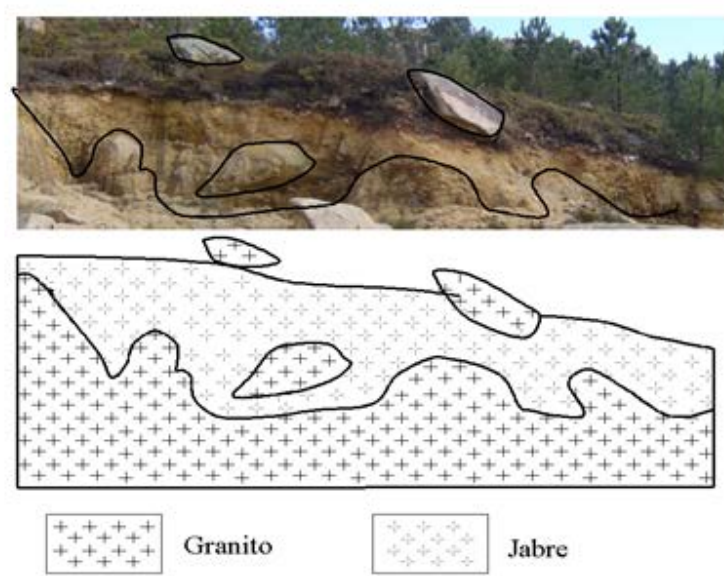

b)

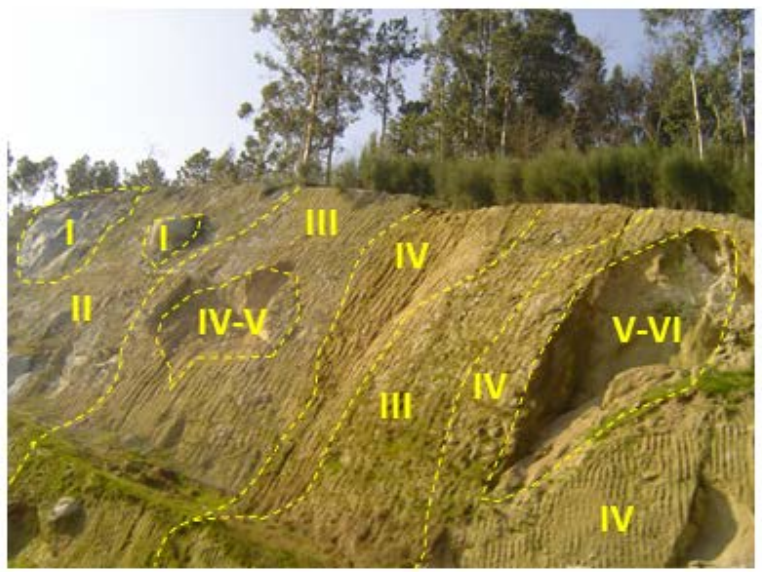

Figura 6. Ejemplos de la heterogénea distribución de la meteorización en los granitos a) Fotografía y croquis geológico de un pequeño talud formado por granito y jabre. b) Fotografía de un talud de unos 20 metros de altura en un macizo granítico con diferentes niveles de meteorización según Moye (1957) marcados sobre el mismo.

Figure 6: Examples of the heterogeneous distribution of weathering in granite a) photograph and geological sketch of a small slope formed by granite and completely decomposed granite (CDG) b) photograph of a slope about 20 metres high in a granite rock mass showing different levels of weathering according to Moye (1957). 
Es por ello que, dada la complejidad de los depósitos, parece recomendable la utilización de métodos de caracterización sencillos y baratos en este tipo de materiales altamente variables tanto en su distribución espacial como en su comportamiento, ya que la realización de ensayos cuidadosos y caros, puede sin embargo no ser representativa de la unidad litológica en su conjunto.

\section{Estabilidad de laderas en jabre (granito descompuesto)}

Se presenta en esta sección el estudio de estabilidad en laderas formadas por granito descompuesto o jabre, que como se ha comentado se comporta como un suelo.

\section{Descripción típica de los fenómenos a estudiar y me- canismos de inestabilidad}

En suelos y macizos rocosos de baja calidad, y en este caso, en laderas formadas por jabre, se observa que los problemas de estabilidad van asociados a una rotura que se produce a través de la masa o el macizo (sin seguir discontinuidades) siguiendo la línea de menor resistencia (Hoek and Bray, 1974). Se puede demostrar que esta línea de menor resistencia en materiales cohesivos-friccionales es una espiral logarítmica y que por tanto se aproxima mucho a un círculo.

La mayoría de las teorías de análisis se basan en que la rotura sigue una superficie de deslizamiento circular. Los círculos de rotura suelen pasar por el pie del talud. En la superficie del terreno aparecen grietas concéntricas y cóncavas hacia la dirección del movimiento, con un escarpe en su parte alta, más acusado cuanto mayor desplazamiento sufra la masa deslizada (Varnes, 1978). En la Figura 7 se muestra un diagrama típico del mecanismo de rotura circular junto con una rotura de este tipo en un talud en jabre recientemente excavado en las obras de una carretera.

Muy comúnmente este tipo de roturas suelen ir catalizadas por la subida de los niveles de agua asociados a periodos de fuerte precipitación, aunque pueden existir otros fenómenos iniciadores de la inestabilidad como los fenómenos de vibración por sismos y voladuras, sobre-excavaciones en la base, etc.

Este tipo de roturas circulares en materiales tipo jabre

a)
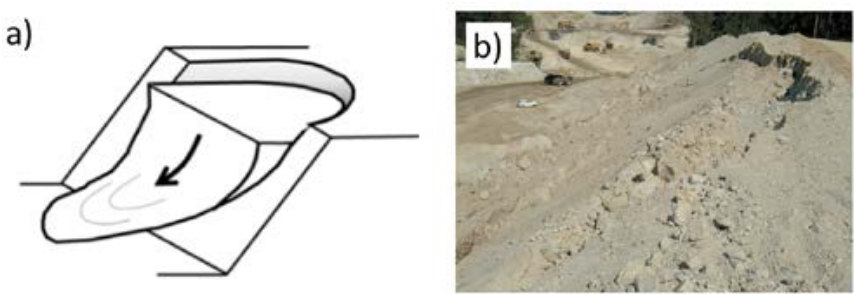

Figura 7. a) Diagrama típico de rotura circular en un talud y b) ejemplo de rotura circular en un talud en jabre en la construcción del segundo cinturón de la ciudad de Vigo.

Figure 7: a) Diagram of a typical rotational failure and b) example of circular failure in a completely decomposed granite (CDG) in the construction of the second ring road around the city of Vigo. es relativamente común en laderas naturales de zonas graníticas húmedas como Galicia, siendo si cabe más común en taludes en obras creadas por el hombre, típicamente en carreteras, lo que se debe a que el proceso

a) Deslizamiento en jabre en el Corredor do Morrazo, según diario local. Abril, 2006.

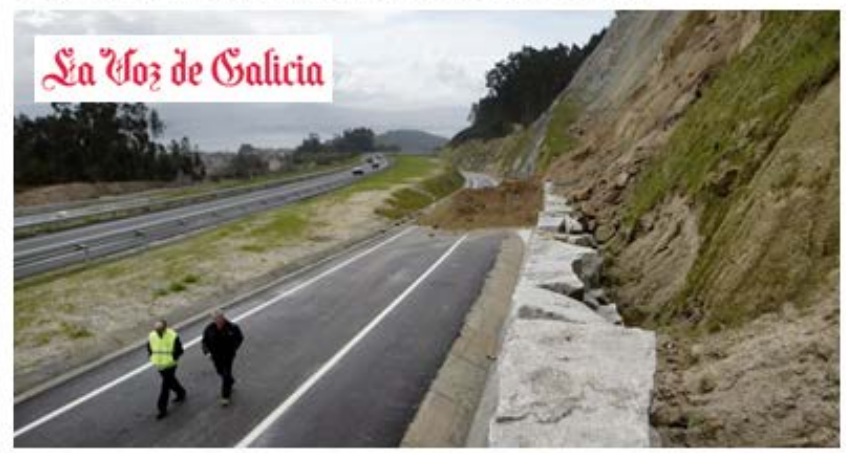

b) Deslizamiento en jabre en la salida de Cangas en el Corredor do Morrazo, según prensa. Marzo, 2014.

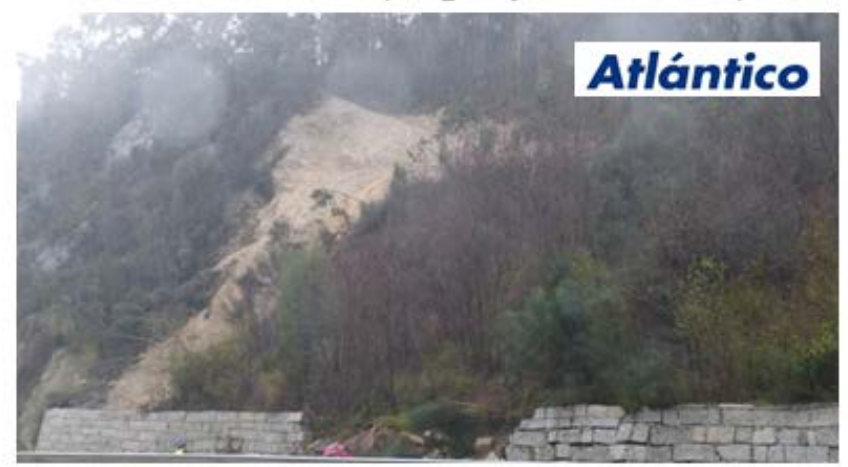

c) Deslizamiento en material tipo jabre en la circunvalación de Vigo, según diario. Marzo, 2019.

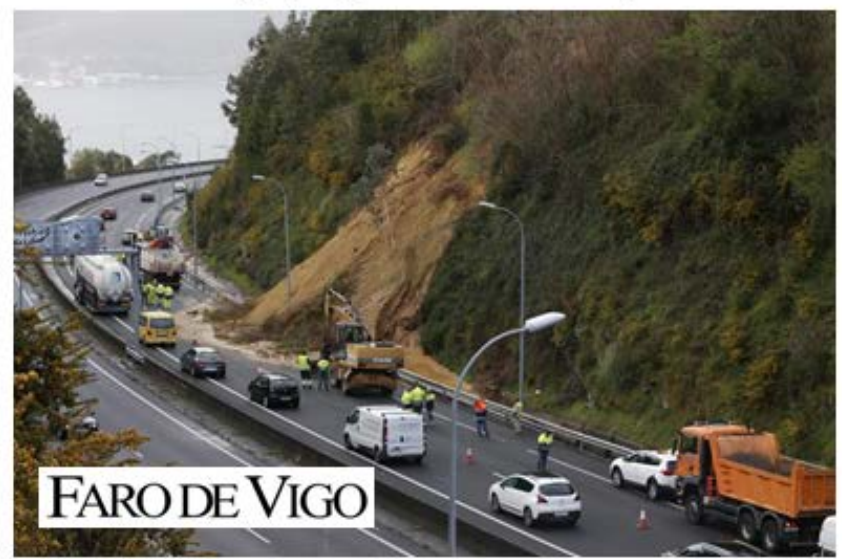

Figura 8. Fotografías de recortes de prensa que reflejan fenómenos de roturas circulares en taludes en jabre, típicamente denominados corrimientos de tierras, en carreteras del entorno de la ciudad de Vigo en Galicia.

Figure 8. Photographs of press clippings that reflect rotational failure events in completely decomposed granite rock cuts on roads around the city of Vigo in Galicia. 
de excavación de dichos taludes suele contribuir a facilitar la meteorización y erosión de dichos jabres.

A manera de ejemplo se presentan en la Figura 8, algunos ejemplos de recortes de prensa de fenómenos de rotura circular o deslizamiento en jabres recogidos a partir de la prensa local en carreteras del entorno de la ciudad de Vigo en Galicia en los últimos años. Estas roturas se suelen producir tras varios días de fuerte precipitación y, como se deduce de la Figura 8, típicamente en primavera, época del año hidrológico en la que solemos encontrarnos una mayor saturación de los taludes.

\section{Una técnica empírica de caracterización de jabres in-situ}

Para el análisis de estabilidad de estas laderas, el aspecto más importante es una buena caracterización geotécnica del material denominado jabre, además de tener un buen conocimiento de la geometría del talud y la presencia de agua.

Como se ha indicado, los jabres, son suelos o rocas blandas derivadas de la meteorización in situ de granito. Desde el punto de vista de la ingeniería geológica, tienen la consistencia de suelos residuales limosos y arenosos de cuarzo y arena. Se trata pues de granitos en los que todo el feldespato se ha caolinizado y la mica se ha descompuesto. Debido al alto porcentaje de granos de cuarzo, este material se ha clasificado a menudo como arena (S). Por ello los jabres tienen una componente de fricción asociada a la presencia de granos de cuarzo, así como una componente cohesiva asociada a la textura de la roca original y la presencia de material arcilloso, resultante de la alteración. Así pues, se puede considerar a los jabres materiales tipo Mohr-Coulomb (cohesivos-friccionales) (Alejano y Carranza-Torres, 2011).

El criterio de rotura de Mohr-Coulomb caracteriza la resistencia al corte del terreno en términos de un valor de cohesión, $c$, y un valor de ángulo de fricción, $\varphi$. El enfoque propuesto para estimar los parámetros $c$ y $\varphi$ de los jabres se basa principalmente en la aplicación de ensayos in situ utilizando un penetrómetro de bolsillo y un molinete o vane-test, como los que se muestra en la Figura 9.a. El penetrómetro de bolsillo se desarrolló originalmente para caracterizar suelos finos y mide resistencias de penetración de hasta 1 MPa (CONTROLS, 2009). Puesto que los resultados obtenidos mediante este ensayo se pueden correlacionar con resultados de penetración estándar (o SPT), es posible obtener una estimación del ángulo de fricción del suelo basado en el parámetro $N$ de la prueba SPT (Hunt, 1984). La veleta está diseñada para determinar la resistencia al corte de los suelos cohesivos y puede medir valores de cohesión de hasta 240 $\mathrm{kPa}$. Estos dispositivos de ensayos son asequibles y los ensayos in-situ planteados han demostrado ser fáciles de realizar en jabres asociados a granitos descompuestos en Galicia.

Al analizarla granulometría y plasticidad de los jabres estudiados por los autores se ha observado que siempre se han podido clasificar como arenas, bien gradadas (SW) o mal gradadas (SP) con pocos finos, o bien con finos limosos poco plásticos (SW-SM) o como arenas limosas (SM). No se descartan clasificaciones tipo SC. De acuerdo con la clasificación del NAVFAC (1971) a este tipo de materiales corresponden cohesiones entre 20 (materiales sueltos) y $50 \mathrm{kPa}$ (compactados) y fricciones entre 34 y $38^{\circ}$. Además, realizando ensayos tipo Hamrol (1961) sobre estos materiales, se obtienen valores del índice de Hamrol entre 15 y $30 \%$ y realizando la aproximación de Rocha (Jiménez-Salas et al., 1981), esto responde a valores de cohesión entre 0 y $100 \mathrm{kPa}$ y fricciones entre 35 y $43^{\circ}$.

Para los jabres estudiados por los autores en varios taludes, los valores de resistencia a la penetración $q_{c}$ obtenidos con el penetrómetro de bolsillo estuvieron en el rango de 0.1 a más de $1 \mathrm{MPa}$. Por lo tanto, asumiendo una relación lineal (lo más simple posible) entre $q_{c} y \tan \varphi$, considerando los rangos de los ángulos de fricción para las diferentes arenas como sugiere Hunt (1984), y basándose en análisis posteriores y ensayos de laboratorio de corte directo junto con mediciones del ángulo de reposo de las pendientes naturales, se propone la relación empírica 1 que se muestra en la Figura 9.b. En dicha ecuación $q_{c}$ es la medida del penetrómetro en MPa.

La naturaleza cohesiva de los jabres va asociada a la presencia de minerales arcillosos (caolinita y halloysita). Para suelos con un componente de resistencia cohesiva significativa (y una fricción reducida), la cohesión se puede estimar utilizando el molinete o vane test (Fig. 9.a). Según la normativa el valor de la resistencia a la compresión para el material, $\sigma_{v}{ }^{c}$ (donde ' $v$ ' significa 'vane-test'), se puede calcular mediante la relación 2 de la Figura 9.b, donde $S_{u}$ es la medida del vane-test. Para materiales cohesivos-friccionales como los jabres, el penetrómetro utilizado para caracterizar el componente de fricción, también se puede usar para inferir valores de cohesión o, alternativamente, el valor de $\sigma_{c}$. La relación entre $\sigma_{p}{ }^{c}$ (donde " $\mathrm{p}$ " significa "penetrómetro") y la fuerza de penetración $q_{c}$ propuesta por Jiménez-Salas et al. (1981) es la que se utilizará para este enfoque según se muestra como relación 3 en la Figura 9.b.

Puesto que las expresiones 2 y 3 de la Fig. 9.b. se utilizan para calcular valores de $\sigma_{c}$ para jabres en condiciones cohesivas y cohesivo-friccionales, se recomienda calcular un promedio ponderado de los dos valores utilizando la relación 4 de la Fig. 9.b, donde $W_{v}$ y $W_{p}$ son factores de ponderación obtenidos de la Tabla de la Figura 9.c según la clasificación del material. Con el valor de $\varphi$ dado por la ecuación 1 de la Figura 9.b. y el valor de $\sigma_{c}$ de la relación 4 de la misma, se obtendrá la cohesión promedio del jabre (ecuación 5 de la Fig. 9.c). Algunas consideraciones más detalladas sobre la aplicación de esta metodología se pueden consultar en Alejano y Carranza-Torres (2011). 
a) Penetrómetro de bolsillo y molinete o 'vane-test'

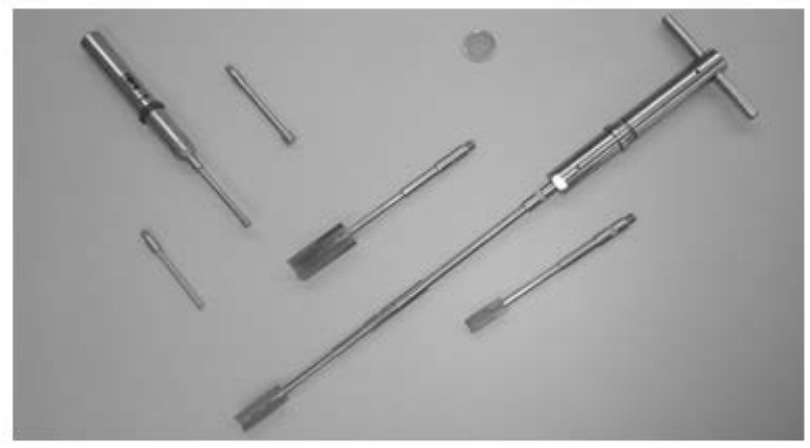

b) Expresiones utilizadas para el cálculo de resistencia

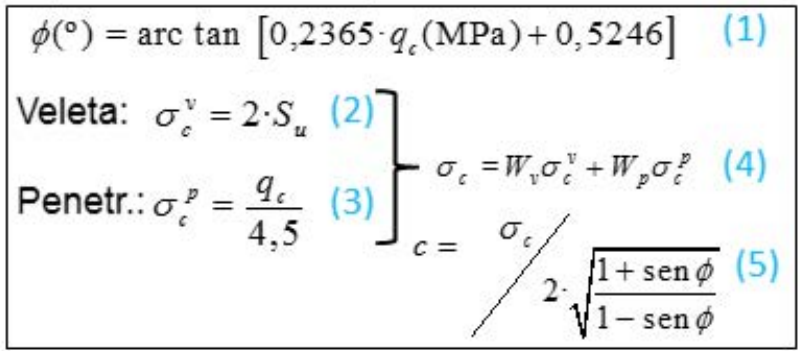

c) Peso del vane test en la ecuación 4

\begin{tabular}{c|c|}
$\begin{array}{c}\text { Clasificación del } \\
\text { suelo }\end{array}$ & $\begin{array}{c}\text { Peso }(\%) \text { delvalor de cohesión derivado del } \\
\text { "vane-test" en la estimación de la cohesión }\left(W_{v}\right)\end{array}$ \\
SP & 25 \\
SW & 30 \\
SW-SM & 40 \\
SM & 50 \\
SC & 60 \\
\hline
\end{tabular}

Figura 9. (a) Fotografías de penetrómetro de bolsillo (izquierda) y molinete o vane-test (derecha), (b) Expresiones para la caracterización de la cohesión y fricción de los jabres, y (c) Tabla de pesos para la caracterización según la clasificación del suelo.

Figure 9. (a) Photographs of pocket penetrometer (left) and vane test (right), (b) Expressions for the characterization of the cohesion and friction of the completely or highly decomposed granites (CDG or $H D G)$, and (c) table of weights for the characterization according to soil classification.

\section{Técnicas de Análisis}

Para analizar la estabilidad frente a roturas circulares hay varios métodos, que comienzan históricamente con el planteamiento del análisis por equilibrio límite del sólido libre que desliza. Con este enfoque, se obtienen más incógnitas que ecuaciones, por lo que hay que acudir a hipótesis adicionales. Hoek y Bray (1974), demostraron que el factor de seguridad (F.S.) real de una rotura circular está más próximo al límite inferior que al superior. Estos autores realizaron los cálculos con dicha hipótesis, obteniendo ábacos (para cinco niveles freáticos: de seco a saturado) que permiten calcular el F.S. del talud.

También basados en técnicas de equilibrio límite se propusieron métodos que dividían a la masa de- slizante en fajas, analizándose la estabilidad de cada una de ellas y del conjunto frente al giro en relación al centro del círculo de rotura. También aquí se obtienen sistemas indeterminados por lo que hay que acudir a ciertas hipótesis para resolverlos. Para cada hipótesis surge un método de fajas, entre los que los más conocidos por su exactitud son los de Janbu (1954) y Bishop (1955), aunque existen versiones actualizadas algo más exactas (GLE). La resolución de estas ecuaciones exige múltiples cálculos y además hay que realizar el cálculo para múltiples posibles círculos de rotura, por lo que se han venido implementando en programas de cálculo que permiten incluir además la presencia de varios materiales, agua y elementos de refuerzo como anclajes, como por ejemplo Slide (Rocscience, 2015). Finalmente, también se puede utilizar métodos numéricos continuos basados en los métodos de diferencias finitas (p.ej. FLAC de la compañía Itasca, 2008) o de los elementos finitos (p.ej. $\mathrm{RS}^{2}$ de la compañía Rocscience, 2017) junto con la técnica de la reducción de la resistencia al corte (Dawson et al., 1999), que permite calcular el F.S. frente a la rotura circular.

Actualmente y fuera de las fases de anteproyecto, los cálculos se suelen realizar utilizando los métodos de fajas, ya que son la opción más eficiente y fácil de usar en problemas sencillos, dan valores equiparables a los de los métodos numéricos y a los resultados que se observan en la práctica; y simplifican la gestión de datos y la realización de análisis de sensibilidad, estadísticos y retrospectivos.

\section{Ejemplo}

Como ejemplo de inestabilidad de una ladera natural en un jabre y para destacar algunas características de este tipo de fenómenos se presenta un caso de una ladera de un valle granítico. La detección del movimiento se produjo a finales de enero de un año muy lluvioso. Se observó la aparición de un escarpe en su parte superior (Fig. 10.c), grietas de compresión a mitad de ladera (Fig.10.b) y fenómenos de abombamiento del terreno en su parte inferior que inclinaron un poste de piedra en la entrada de una finca (Fig.10.d). El arenamiento del granito para dar jabre (Fig. 10.a) junto con las observaciones realizadas indicaban que se trataba de una rotura circular rotacional clásica (Fig. 10.e) en jabre.

Para estudiar esta rotura se realizó primero una topografía de detalle, se visitó la zona inventariando los puntos de agua, se tomaron muestras de jabre para clasificar como suelos, se hicieron ensayos de densidad-in-situ y se realizaron ensayos de penetrómetro y vane-test en unos 25 puntos del talud, tal y como se refleja en la Figura 11. En base a la clasificación como suelo y a ensayos in-situ se caracterizó el terreno desde el punto de vista geomecánico e hidrogeológico. Se estimó de esta manera, una densidad media sin-situ del jabre de $1620 \mathrm{~kg} / \mathrm{m}^{3}$, mientras que la saturada sería $1810 \mathrm{~kg} / \mathrm{m}^{3}$ y se estimó además un coeficiente de permeabilidad aproximado de $\mathrm{k}=1,75 \mathrm{e}-4 \mathrm{~m} / \mathrm{s}$. Los 
valores de cohesión y fricción media estimados según la metodología descrita en la sección anterior serían $28.5 \mathrm{kPa}$ y $33.5^{\circ}$, respectivamente. A partir de la geometría se obtuvo el perfil del terreno. También se recopilaron los datos de precipitación de la estación meteorológica más próxima a la zona, y basados en ellos se pudo comprobar la influencia del agua en la respuesta del terreno atendiendo al nivel de precipitación recibido por la zona.

Los dos aspectos claves en el análisis de estabilidad realizado con métodos de fajas (Bishop y Janbu) y numérico (MDF con el código FLAC), eran identificar la posición del contacto entre el jabre tal y como se encontraba en superficie y un material menos meteorizado (granito sano) así como la posición del nivel freático. Para estudiar lo primero, se probaron varias posiciones tentativas, partiendo una razonable que se refleja en el perfil de la Figura 12. Se constató que, aunque se sitúe el contacto más debajo de esta, el F.S. apenas varía, por lo que esto sirvió para demostrar como el uso de técnicas de análisis contribuye a la caracterización de los terrenos. Adicionalmente y como se muestra la Figura 6 en muchas ocasiones estos contactos son bastante irregulares por lo que incluso una malla de sondeos muy cerrada no permite conocer en detalle la superficie de contacto y los enfoques como el propuesto son más prácticos.

En cuanto a la posición del nivel freático, teniendo en cuenta el nivel de precipitación, la posición del nivel freático en la zona alta del talud (donde aflora la roca) y la permeabilidad estimada a partir de las clasificaciones de suelos se estimaron las posiciones del nivel freático para la situación en la que se produjo el deslizamiento, para una situación típica de un invierno normal (no muy lluvioso) y para una situación

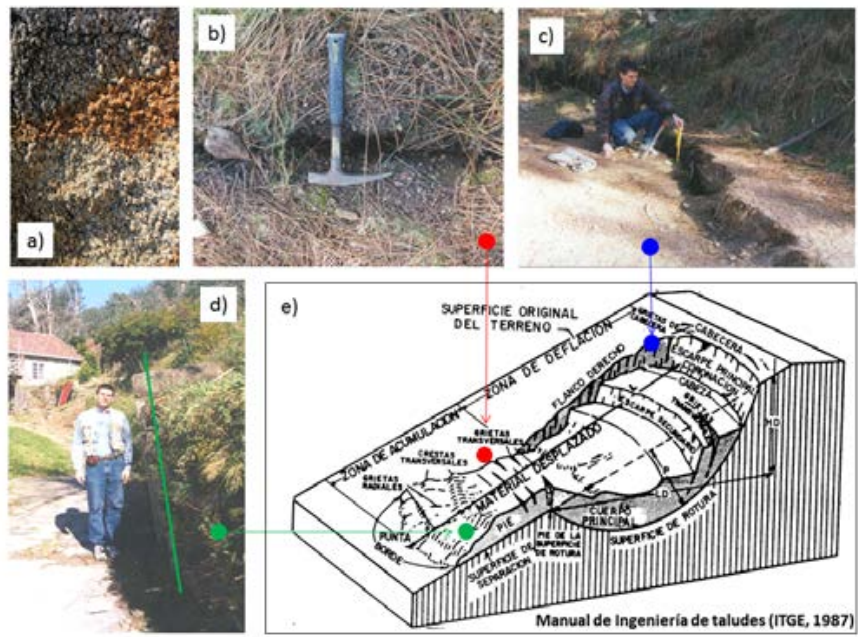

Figura 10. Esquema de una típica rotura circular según ITGE (1987) y elementos identificadores de una rotura rotacional en una ladera en jabre, explicados en el texto.

Figure 10. Sketch of a typical circular failure according to ITGE (1987) and elements identifying a rotational failure in a natural slope in completely decomposed granite, as referred to in the main text.

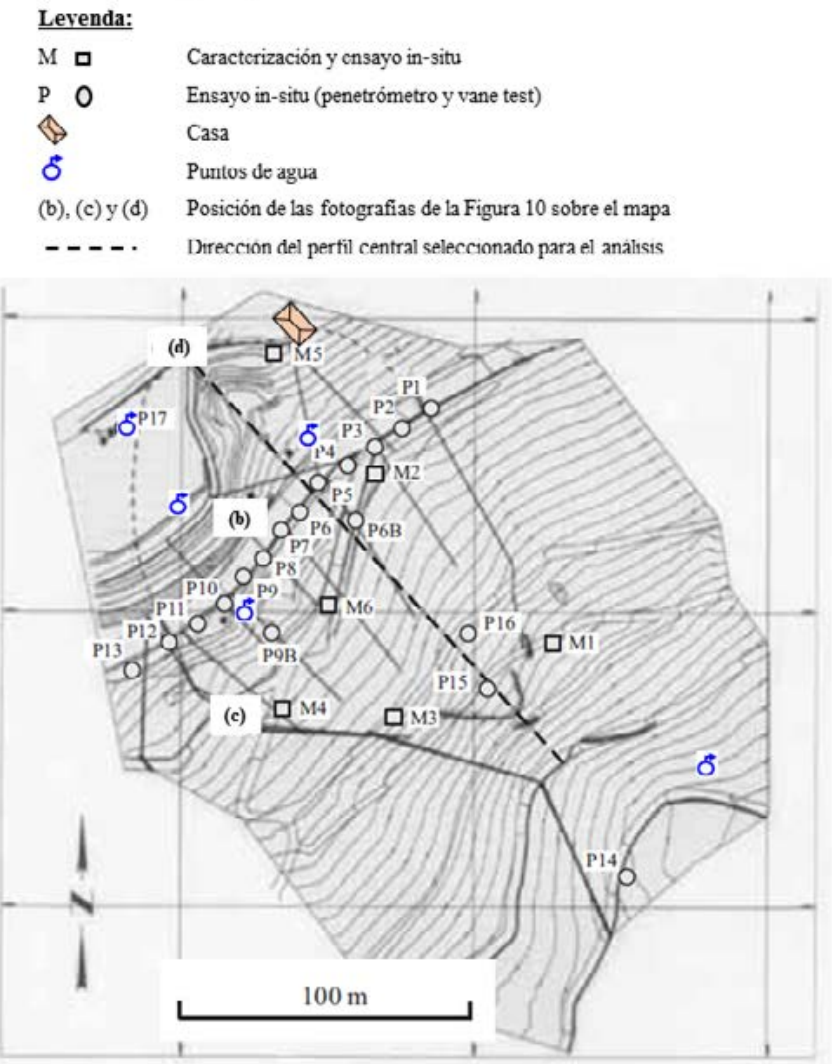

Figura 11. Plano esquemático de la ladera estudiada. Las ubicaciones de los puntos de muestreo y ensayo in-situ (incluyendo penetrómetro y vane test) se indican como puntos " $M$ " $\mathrm{y}$ " $P$ ".

Figure 11. Schematic plan view map of the hillside studied. The locations of the sampling and in-situ test points (including penetrometer and vane test) are indicated as " $M$ " and " $P$ " points.

$$
\text { Métodos de equilibrio límite de fajas }-\left[\begin{array}{ll}
\underline{\text { Janbu }} & F o S=1.01 \\
\text { Bishop } & F o S=1.10
\end{array}\right]-F \circ S=1.05
$$

Método numérico basado en diferencias finitas (FLAC) FLAC (TRRC) FoS $=1.03$

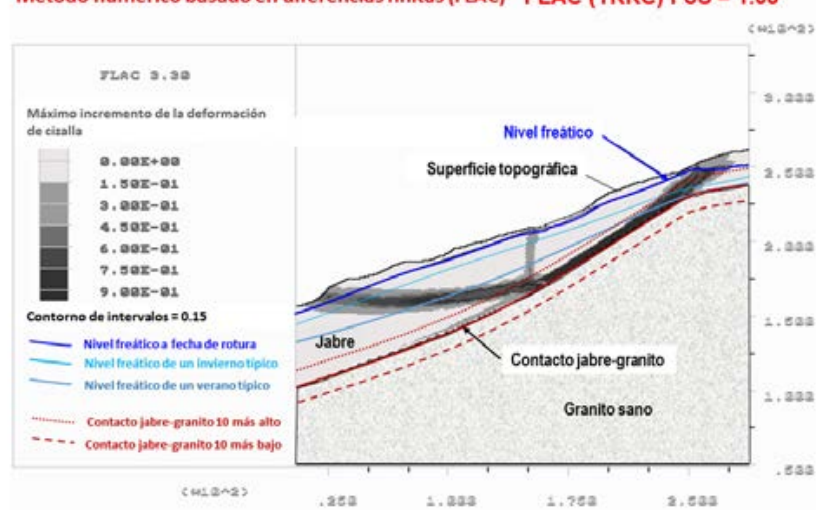

Figura 12. Representación esquemática del perfil interpretado según FLAC, Y F.S. de obtenidos. Se incluyen los tres niveles de nivel freático analizados y el contacto del granito sano y el jabre a lo largo de la dirección del perfil central indicado en la Figura 11.

Figure 12. Cross-cut section of the studied profile interpreted according to FLAC, and obtained FoS (factor of safety). It includes the three water table levels analyzed and the estimated contact of the sound granite and the CDG in the direction of the central profile marked on the map in Figure 11. 
típica de verano (Figura 12). Finalmente, utilizando los métodos fajas y numérico se constató que para la situación en la que se produjo el movimiento de tierras el F.S. sería 1.05 como media de los métodos de fajas y 1.03 según el método numérico. Adicionalmente se presentan en la Tabla 1 los F.S. obtenidos para otras situaciones explicadas anteriormente, que justifican los resultados obtenidos.

Puesto que el deslizamiento fue claramente asociado a la cantidad de agua acumulada en el talud, se recomendaron medidas preliminares para evacuar dicha agua mediante drenes californianos y zanjas de salida del agua, procediéndose a una remodelación del talud un año después en paralelo con obras de mejora de la carretera que lo atravesaba.

\begin{tabular}{llllll}
\hline Contacto & Freático & F.S. Bishop & F.S. Janbu & F.S. fajas & F.S. FLAC \\
\hline Típico & Estimado & 1.11 & 1.01 & 1.05 & 1.03 \\
Típico & Invierno & 1.46 & 1.35 & 1.40 & 1.36 \\
Típico & Verano & 1.68 & 1.56 & 1.62 & 1.57 \\
$10 \mathrm{~m}$ más alto & Estimado & 1.23 & 1.21 & 1.21 & 1.20 \\
$10 \mathrm{~m}$ más bajo & Estimado & 1.11 & 1.01 & 1.06 & 1.02
\end{tabular}

Tabla 1. Resultados del F.S. para varias situaciones de la ladera bajo estudio.

Table 1: F.S. results for several situations of the slope under study.

\section{Estabilidad y riesgo por desprendimientos en zonas con procesos de meteorización activos}

Se presentan en este apartado consideraciones relativas a la gestión de la estabilidad y, principalmente los desprendimientos en laderas graníticas formadas por bolos de tamaño mediano.

\section{Descripción típica de los fenómenos a estudiar y me- canismos de inestabilidad y desprendimiento}

Como se ha indicado e ilustrado por medio de las Figuras 4 y 5 , es relativamente común encontrar laderas en terreno graníticos formadas por bolos de tamaño mediano, esto es entre $1 \mathrm{dm}^{3}$ y un $\mathrm{m}^{3}$ que ocupan grandes áreas de las laderas, acompañadas localmente por materiales más finos e incluso zonas con granito descompuesto o jabre. En estas condiciones la predicción de la inestabilidad es compleja. En general las técnicas viables más razonables para su estudio pasan por estimación de la estabilidad de los bloques aparentemente más proclives a moverse y a continuación estudiar su posible trayectoria ladera abajo para cuantificar la probabilidad de que impacten zonas habitadas o infraestructuras.

En lo que respecta a la estabilidad de cada bloque, se puede analizar su estabilidad frente a deslizamiento y vuelco, siguiendo técnicas clásicas (Hoek and Bray, 1974), que es necesario adaptar a las condiciones encontradas, como se verá en el apartado 5 . En cuanto al estudio de la trayectoria de los bloques ladera abajo se han desarrollado en los últimos años estudios de analizan en detalle los tipos de movimiento y parámetros asociados, así como programas que los implementan (por ejemplo, RocFall de Rocscience, 2017; o Agliardi and Crosta, 2003). Los modelos más usados son los de partícula por su facilidad de uso, pero necesitan de un adecuado ajuste de los parámetros (Giani et al., 2004; Alejano et al., 2007).

Como, a veces, es difícil aplicar estas técnicas, otro posible enfoque que se puede además considerar complementario al anterior, es la aplicación de métodos empíricos que permiten una estimación o cuantificación del riesgo por desprendimientos. Estos métodos comenzaron a desarrollarse en los 90 y suelen ser de aplicación específica, por ejemplo, a carreteras (RHRS de Pierson et al., 1990), canteras (Alejano et al., 2008) o zonas habitadas (Mölk et al., 2008). Precisan de datos variados y pueden servir de ayuda para tomar decisiones. Nos remitimos a la bibliografía señalada para consultar su aplicación.

\section{Técnicas de caracterización}

La caracterización de estas laderas formadas por bloques requiere analizar un buen número de datos. En primer lugar, hay que realizar una caracterización geotécnica de las discontinuidades en roca in-situ, cuantificando además de su orientación los parámetros geotécnicos más relevantes que incluyen espaciado, continuidad, rugosidad, resistencia, apertura, relleno y presencia de agua. Esta caracterización permitirá identificar fenómenos de inestabilidad y estimar tamaños de bloque. Conviene identificar sobre el terreno o con ayuda de fotografía las distintas zonas del talud en lo que respecta a la respuesta ante un bloque que cae, que se cuantificará en términos de coeficientes de restitución. Es también necesario conocer datos climáticos, sobre todo la precipitación, así como el nivel sísmico, por ejemplo, en términos de aceleración horizontal máxima esperable, ya que a veces los sismos provocan la inestabilidad.

La geometría de los taludes y de los bloques es importante. Aunque en el pasado se partía de topografías groseras, típicamente a escalas 1:10.000; hoy en día conviene tener un conocimiento de la geometría muy detallado, que se puede obtener por técnicas de escaneado laser y/o fotogrametría desde dron. Basándose en estas técnicas se obtienen nubes de puntos que representan fielmente la geometría de las laderas, y de las que se puede sacar incluso información de la forma y tamaño de los bloques de roca sueltos. Esta topografía debe recoger las zonas de posible afectación, como carreteras y sus características, edificaciones y otras infraestructuras, zonas de paso o zonas habitadas.

Finalmente conviene realizar vistas a la zona para identificar los bloques potencialmente inestables y cuantificar en la medida de lo posible in-situ su nivel de estabilidad. Si se identifican bloques que han sufrido procesos de desprendimiento conviene realizar un 
pequeño censo identificando su posición y características ya que pueden contribuir a aquilatar los modelos de trayectorias de bloques. A su vez la caracterización se debe basar parcialmente en las técnicas que proporcionen datos que se prevean que van a ser utilizadas, y que pueden variar en función de las circunstancias. En este sentido, acudir a los métodos empíricos en las fases iniciales de los estudios puede contribuir a mejorar la caracterización.

\section{Técnicas de análisis}

Como técnicas de análisis que se ilustraran mediante el ejemplo del siguiente sub-apartado indicamos dos enfoques que se pueden utilizar por separado, aunque dada la naturaleza compleja de los fenómenos a estudiar conviene aplicarlos en paralelo.

El primero, de base más teórica, llevaría consigo en primer lugar la identificación de los bloques o zonas del talud que pudieran sufrir procesos de inestabilidad. Para cada uno de los bloques o zonas habría que estudiar o cuantificar su nivel de estabilidad obteniéndose idealmente una probabilidad de que la inestabilidad se produzca. Se pueden utilizar para ello, técnicas de análisis de estabilidad clásicas frente a rotura plana, en cuña, vuelco, etcétera, junto con un método estadístico como el de Montecarlo. Así se obtendría la probabilidad de inestabilidad. Si nos es posible la cuantificación exacta, se puede acudir a técnicas estimativas para estimar la probabilidad de inestabilidad, como se verá en el ejemplo.

Una vez conocidas e identificadas las zonas fuente se analizarían las trayectorias de las rocas inestables a lo largo de la ladera. Para ello se usan programas de partícula en dos o tres dimensiones. Una adecuada cuantificación estadística de los coeficientes de restitución que marcan la respuesta de un bloque al rebotar con el terreno es absolutamente prioritaria para obtener respuestas realistas. Estos parámetros se pueden aquilatar si se dispone de un buen censo de bloques desprendidos en el pasado. También es muy relevante disponer de una geometría del terreno lo más exacta posible, idealmente basada en nube de puntos obtenidas con Laser escáner y/o fotogrametría de dron. A partir de las trayectorias calculadas con estos programas se puede cuantificar la probabilidad de que un bloque impacte en un edificio o una carretera, y en función de la misma, tomar las medidas correctoras que se consideren apropiadas y que pueden incluir mallas para reforzar el terreno, cunetas o bermas, pantallas estáticas o dinámicas (cuando la energía con que descienden los bloques sea muy elevada) o falsos túneles.

El segundo enfoque, de base empírica, pasa por la aplicación de métodos de cuantificación de riesgo. Para el caso de carreteras, el método más usado es el denominado Rockfall Hazard Rating System o RHRS. Para zonas de alta montaña se puede aplicar la metodología denominada $\mathrm{R}^{3} \mathrm{~S}^{2}$, especialmente diseñada para valles alpinos. En todo caso la aplicación de estas metodologías debe adaptarse a las particularidades del caso bajo escrutinio.

EI RHRS (Pierson et al., 1990) fue desarrollado para evaluar el riesgo por desprendimientos en carreteras americanas. Nació como respuesta a la necesidad de establecer métodos de evaluación de riesgos por desprendimientos en carreteras, hasta entonces basado en apreciaciones subjetivas y control de costes. EI método no indica explícitamente si el nivel de riesgo es aceptable o no, simplemente sirve para priorizar los problemas a resolver a partir de una ordenación de taludes según su RHRS y las disponibilidades económicas. Por ejemplo, para taludes en carreteras norteamericanas, se definieron como taludes que requieren acción inmediata los que dan valores de más de 500 , mientras que son de baja prioridad aquellos con valores inferiores a 300 .

Dado que el riesgo por desprendimientos afecta más a la población civil en áreas pobladas que en carreteras o minas Mölk et al. (2008) propusieron un método empírico diferente, $\mathrm{R}^{3} \mathrm{~S}^{2}$, basado en los parámetros RHRS, pero adaptado a las condiciones de áreas pobladas en los Alpes austríacos y enfocándose en estimar de manera cuantitativa indirecta la probabilidad de accidentes en áreas habitadas permanentemente. Se propuso que el enfoque fuera de ayuda en la gestión del riesgo, la priorización de áreas a proteger y para la ejecución de medidas de control para mitigar el riesgo.

\section{Ejemplo}

Tras un incendio forestal, se observó que un otero de roca granítica erosionada habitado en su base podía ser susceptible a fenómenos de desprendimientos. Se resume brevemente en lo que sigue un estudio de enfoque múltiple del riesgo de caída de rocas en la zona en cuestión, localizada en el Concello de Nigrán (Pontevedra). La Figura 13 muestra la vista aérea de la zona antes el incendio y tres vistas del monte tras el incendio. Se observa como la ladera es un ejemplo típico de ladera granítica (tipo inselberg) formada por múltiples bloques de roca de tamaño medio, muchos de los cales han sufrido desplazamientos, tal y como se describió en la primera parte del artículo.

Primero se tomaron todos los datos necesarios para conocer la ladera incluyendo los aspectos indicados en el apartado 4.2. Esto incluyó un estudio geotécnico clásico, datos meteorológicos y sísmicos y se obtuvo una nube de puntos muy detallada de toda la zona mediante la combinación de diferentes técnicas de detección remota (fotogrametría de dron y LiDAR). Además, a partir de la nube de puntos se realizó un análisis geoestructural semiautomático (Riquelme et al., 2014) que permitió obtener el tamaño de bloque medio de granito en la ladera, de en torno a $0.9 \mathrm{~m}^{3}$ (Pérez-Rey et al., 2019a). Una vez que se disponía de dicha información, se realizó un reconocimiento de 
campo detallado donde se identificaron todos los bloques, conjuntos de bloques y zonas potencialmente inestables, así como la presencia de bloques caídos en el pasado. Cada una de estas zonas marcadas en foto aérea en la Figura 14 fue geo-referenciada y se realizó una estimación de los posibles mecanismos de inestabilidad y la probabilidad de inestabilidad de cada zona en términos de niveles de riesgo. De forma ilustrativa se presentan algunos bloques analizados en la Figura 15.
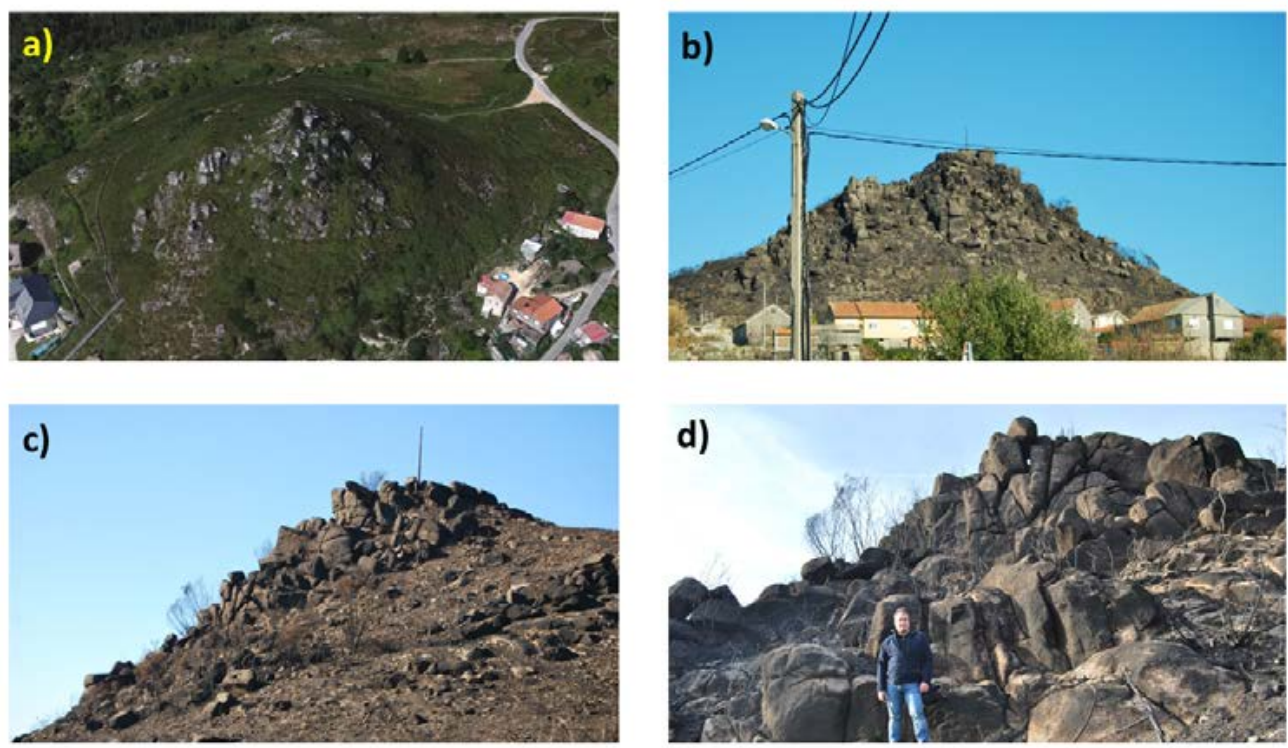

Figura 13. Imágenes de la ladera a) antes del incendio tomada de Google Earth '2017 Google' y fotografías del otero después del incendio desde las zonas b) sur, donde se sitúan las viviendas, c) oeste y d) este.

Figure 13. Images of the slope a) before the fire, taken from Google Earth '2017 Google' and photographs of the hill after the fire from b) south, where the houses are located, c) west and d) east.

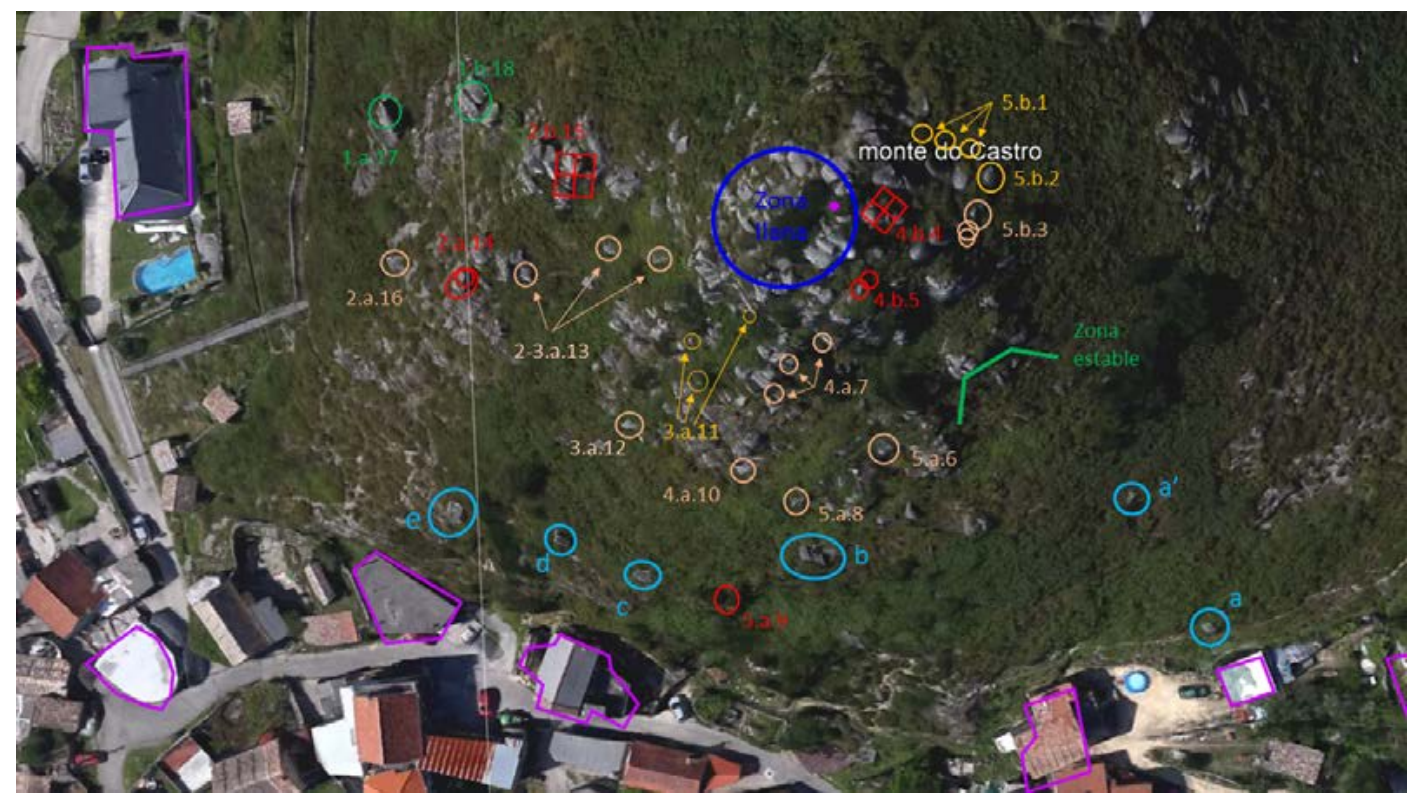

Figura 14. Foto aérea donde se indican todas las zonas de inestabilidad posibles observadas. Con código numérico, los cuadrados se refieren a zonas de macizo rocoso in-situ y los círculos se refieren a bloques que no están en su posición original. Con letra, en los círculos azules se marcan los bloques caídos en el pasado y en morado se marcan la posición de los edificios que se pretende proteger del impacto de rocas.

Figure 14. Aerial photo where all possible instability zones observed are indicated. With a numeric code, the squares refer to areas of insitu rock mass and the circles refer to blocks that are not in their original position, they are already detached. With a letter code, in the blue circles are marked the blocks fallen in the past. In purple, the position of the buildings that should be protected from the impact of rocks, are highlighted. 

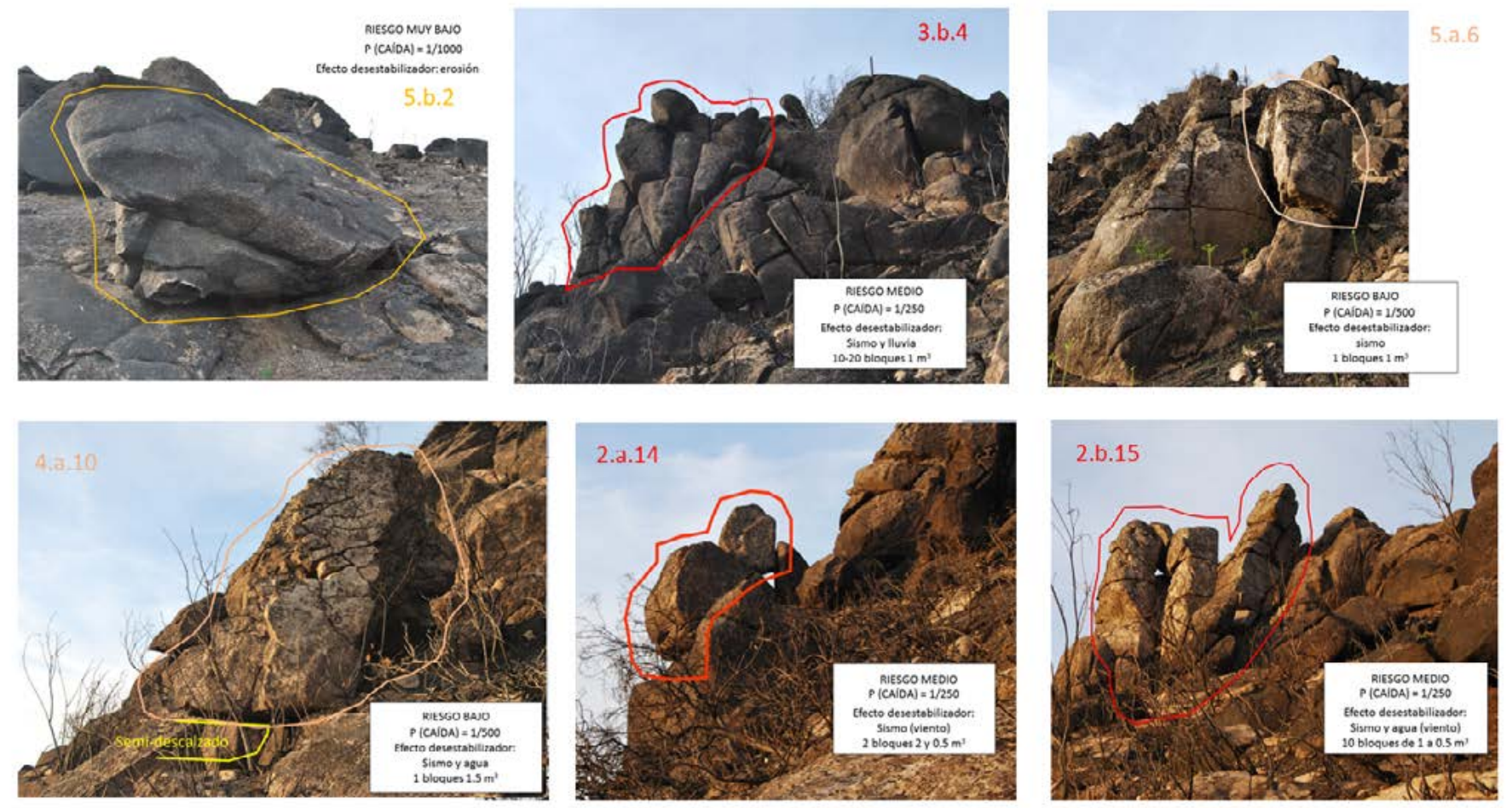

Figura 15. Algunos ejemplos de zonas identificadas como potencialmente inestables observadas en campo, con indicación del nivel de riesgo, potenciales efectos desestabilizadores y volumen estimativo.

Figure 15. Some examples of areas identified as potentially unstable observed in the field, indicating the level of risk, potential destabilizing effects and estimated volume.

En la Tabla 2, a cada uno de estos bloques o conjuntos de bloques se le ha asignado la probabilidad anual de desestabilización asociada a los niveles de riesgo estimados: esto es valores de 1/100, 1/250, 1/500, 1/1000 y 0 para niveles de riesgo ALTO, MEDIO, BAJO, MUY BAJO y nulo, respectivamente. La probabilidad antedicha iría asignado bloque por bloque, por lo que en cada caso se podría calcular la probabilidad de no ocurrencia de la desestabilización (reflejada en la última columna de la Tabla 2, como 1 (probabilidad absoluta) menos la probabilidad de ocurrencia del fenómeno. La probabilidad de no ocurrencia de la desestabilización de todos los casos conjuntamente se calcularía como el producto de las probabilidades individuales de cada evento (estabilidad) que aparecen en la última columna de la tabla anterior, para la que se obtendría un valor de 0.8814 . Consecuentemente, la probabilidad anual de ocurrencia de un fenómeno de desestabilización sería 1 menos la probabilidad de no ocurrencia y por tanto 0.1186 . Esto es sería de entorno al 12 por ciento, lo que se traduce en que cabría esperar que se inicie un proceso de desestabilización de bloques cada 8 o 9 años. Dado el carácter estimativo de estos cálculos y errático de estos fenómenos podría considerarse razonable entre cada 5 y 10 años.

Dado que la respuesta de la roca que desciende por la ladera depende de la geometría de los taludes en gran medida, para el análisis de trayectoria se partió de la nube de puntos y partiendo de las zonas fuentes

\begin{tabular}{lllllll}
\hline & POSICIÓN & tamaño $\left(\mathrm{m}^{3}\right)$ & $\mathrm{n}^{\circ}$ bloques & Riesgo & probabilidad & prob no \\
\hline 1 & $4 . \mathrm{b}$ & 1,5 & 3 & MUY BAJO & 0.001 & 0.997 \\
2 & $5 . \mathrm{b}$ & 1,5 & 1 & MUY BAJO & 0.001 & 0.999 \\
3 & $4 . \mathrm{b}$ & $0,5-2$ & 3 & BAJO & 0.002 & 0.994 \\
4 & $4 . \mathrm{b}$ & 1 & 8 & MEDIO & 0.004 & 0.968 \\
5 & $4 . \mathrm{a}$ & 1 & 2 & MEDIO & 0.004 & 0.992 \\
6 & $5 . \mathrm{a}$ & 1 & 1 & BAJO & 0.002 & 0.998 \\
7 & $4 . \mathrm{a}$ & 0,5 & 3 & BAJO & 0.002 & 0.994 \\
8 & $5 . \mathrm{a}$ & 0,5 & 1 & BAJO & 0.002 & 0.998 \\
9 & $5 . \mathrm{a}$ & 0.5 & 1 & MEDIO & 0.004 & 0.996 \\
10 & $4 . \mathrm{a}$ & 1,5 & 1 & BAJO & 0.002 & 0.998 \\
11 & $3 . \mathrm{a}$ & $0.5-1$ & 3 & MUY BAJO & 0.001 & 0.997 \\
12 & $3 . \mathrm{a}$ & 1,5 & 1 & BAJO & 0.002 & 0.998 \\
13 & $2-3 . \mathrm{a}$ & $0,5-1$ & 3 & BAJO & 0.002 & 0.994 \\
14 & $2 . \mathrm{a}$ & $0,5-2$ & 2 & MEDIO & 0.004 & 0.992 \\
15 & $2 . \mathrm{b}$ & $0,5-1$ & 10 & MEDIO & 0.004 & 0.961 \\
16 & $2 . \mathrm{a}$ & 1,5 & 1 & MUY BAJO & 0.001 & 0.999 \\
17 & $1 . \mathrm{a}$ & 1 & 1 & NULO & 0 & 1 \\
18 & $1 . \mathrm{b}$ & 2 & 1 & NULO & 0 & 1
\end{tabular}

Tabla 2. Estimación grosera de la probabilidad de potencial inestabilidad.

Table 2. Rough estimate of the probability of potential instability.

se tomaron como perfiles las trayectorias de las líneas de máxima pendiente sobre el terreno tal y como se muestran en la Figura 16. Para realizar las simulaciones se utilizó el código de partícula bidimensional RocFall 4.0. (Rocscience, 2012) y se realizó una cuantificación detallada de los parámetros de restitución a partir de la experiencia de los autores. Para cada uno de los perfiles representados en la Fig. 16 se simuló la liberación de 1000 bloques desde las zonas fuente 

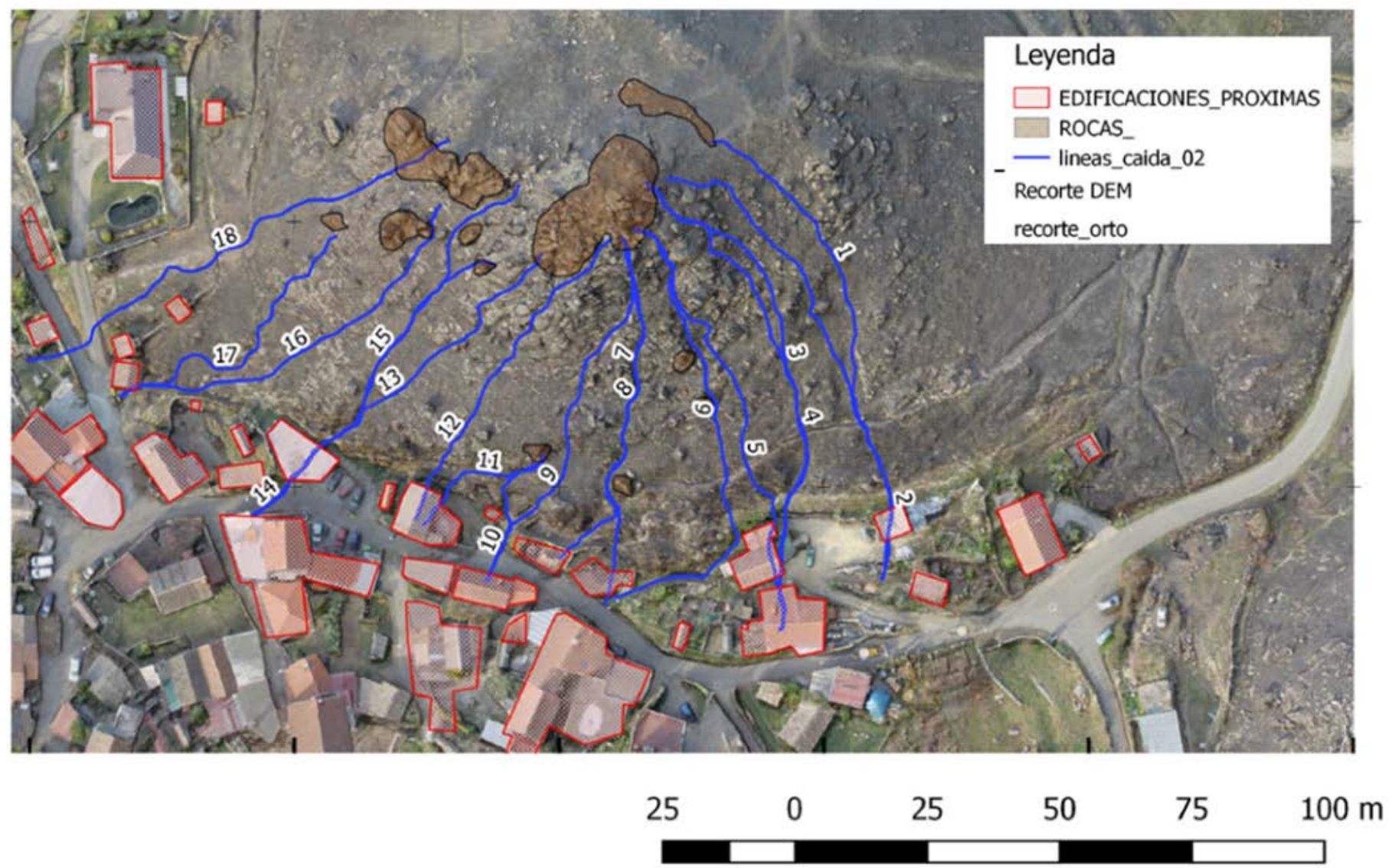

Figura 16. Cálculo de las líneas de caída por máxima pendiente, basadas en la nube de puntos, partiendo de zonas fuente sobre la foto aérea de detalle, junto con la nomenclatura de las edificaciones.

Figure 16. Calculation of the rock-fall paths following the maximum slope trajectories, based on the point cloud, starting from source areas on the detailed aerial photo, together with the names given to buildings.

de los taludes. El peso asignado a los bloques fue de $2600 \mathrm{~kg}$ (equivalente a algo menos de $1 \mathrm{~m}^{3}$ ) con una desviación estándar de $1000 \mathrm{~kg}$, valor necesario para conocer la energía asociada a los bloques al caer.

Los resultados de estas simulaciones permiten observar las trayectorias de los bloques deprendidos, las posiciones finales de los bloques, las envolventes máximas de alturas de tránsito de los bloques y de la energía cinética de los bloques, entre otros parámetros. Como ejemplo se muestran en la Figura 17 los resultados de la simulación correspondiente a la línea de caída $\mathrm{n}^{\circ} 12$. Los resultados de alcance de los bloques de todas las simulaciones se muestran en la Tabla 3 , donde se han incluido los alcances para varios porcentajes, y en su caso, el porcentaje de bloques que impacta con alguna edificación.

En esta tabla observa que en las líneas de caída laterales $(1,2,16,17$ y 18$)$ de perfil más tendido los bloques no alcanzan zonas habitadas, como ocurre para algunas otras líneas de caída $(4,6$ y 8$)$ en zonas más Ilanas. En el resto de trayectorias los bloques impactarían sobre edificaciones, en particular para la mayoría de trayectorias centrales $(5,7,9,12$ y 13$)$, asociadas a perfiles más escarpados, el porcentaje de bloques golpearían las casas pasaría a valores por encima del $1.5 \%$ alcanzando más del $5 \%$ en el caso de la línea de caída 12, esto es, más de 1 bloque de cada 20 podría alcanzar la casa denominada Casa S.

\begin{tabular}{|c|c|c|c|c|c|c|}
\hline Sección & $75 \%$ & $90 \%$ & $95 \%$ & $99 \%$ & $100 \%$ & ¿Afección? \\
\hline 1 & 23.8 & 32.9 & 33.2 & 38.4 & 46.2 & NO \\
\hline 2 & 35.3 & 42.8 & 48.5 & 58.8 & 73.9 & NO \\
\hline 3 & 45.3 & 52.1 & 55.1 & 59.0 & Casa E & CASA E $-0.2 \%$ \\
\hline 4 & 47.2 & 50.2 & 54.2 & 61.2 & 74.1 & No \\
\hline 5 & 35.1 & 41.3 & 48.4 & Casa E & & CASA E $2.1 \%$ \\
\hline 6 & 35.3 & 42.8 & 48.5 & 58.8 & 73.9 & NO \\
\hline 7 & 31.6 & 46.9 & 52.4 & Galpón & & GALPÓN $1.5 \%$ \\
\hline 8 & 30.2 & 45.5 & 52.1 & 57.2 & 68.9 & NO \\
\hline 9 & 35 & 51.7 & 54 & Merendero & & MERENDERO $-4.4 \%$ \\
\hline 12 & 36 & 46.1 & Casa S & & & CASA S $-5.2 \%$ \\
\hline 13 & 37.9 & 51 & 57.9 & Casa W & & CASA W $-3.2 \%$ \\
\hline 14 & 24 & 28 & 31.5 & 42.1 & Casa W & CASA W $-0.5 \%$ \\
\hline 15 & 24.5 & 32.5 & 35.1 & 52.7 & Casa W & CASA W $-0.4 \%$ \\
\hline 16 & 21.1 & 25.7 & 37.2 & 47.2 & 49.5 & NO \\
\hline 17 & 4.7 & 5 & 5.5 & 5.6 & 5.7 & NO \\
\hline 18 & 28.1 & 30.9 & 38.5 & 42.3 & 49.0 & No \\
\hline
\end{tabular}

Tabla 3. Alcances (en metros desde el punto inicial) de los bloques por porcentajes para cada línea de caída y porcentaje de bloques que impactan sobre las edificaciones para cada línea de caída.

Table 3. Distances (in metres from the initial point) of the blocks by percentage for each fall line and percentage of blocks impacting the buildings for each fall line. 
LÍNEA DE CAIIDA 12

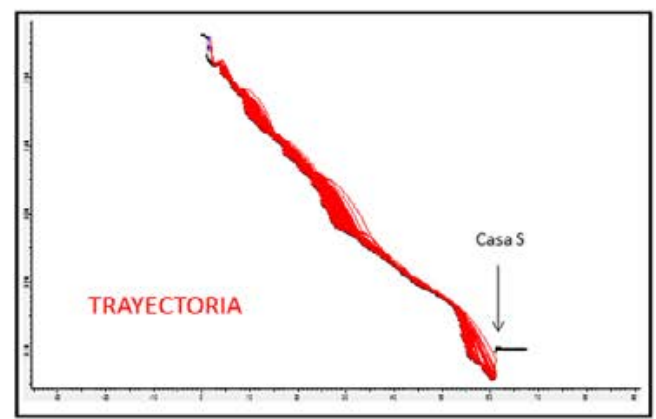

Trayectorias de desprendimiento

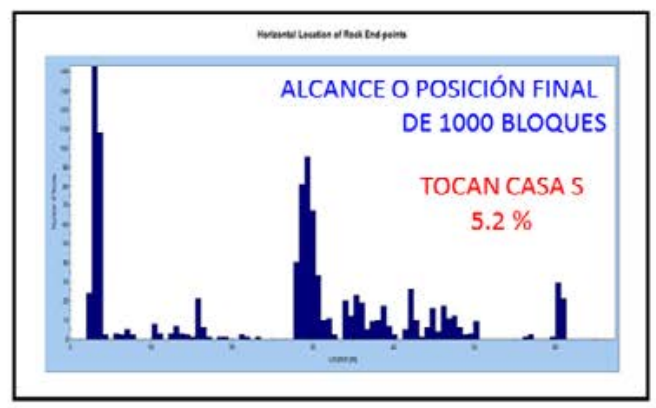

Alcance de los bloques
LÍNEA DE CAÍDA 12

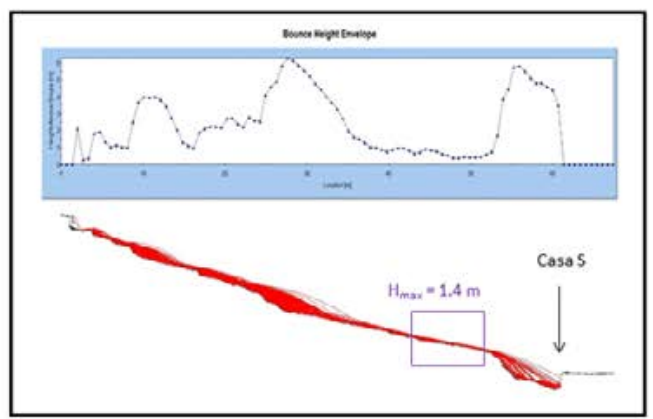

Envolvente de alturas de trayectoria

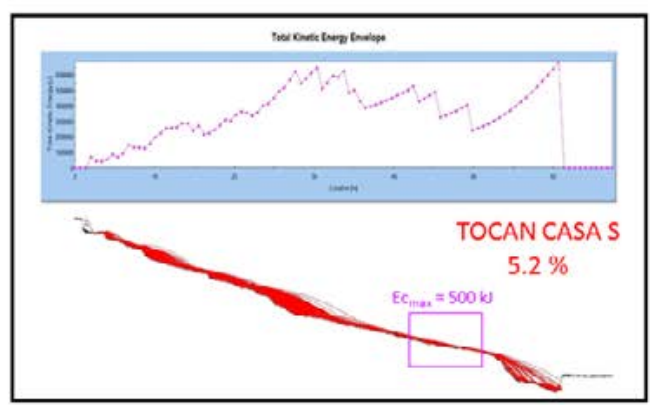

Envolvente de energía cinética total

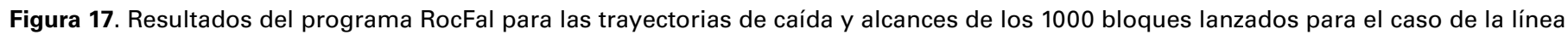

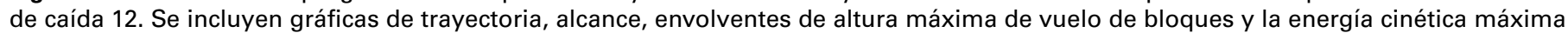
conjunta.

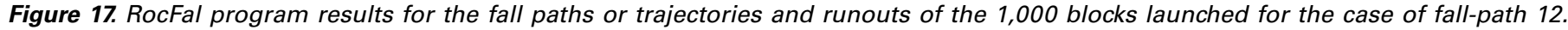
Graphs of fall path, runout distances, envelopes of maximum block bounce height and kinetic energy are included.

Así pues, el riesgo por desprendimientos de la zona central de la ladera, esto es, el riesgo combinado de existencia de fenómenos de inestabilidad en zonas fuente y trayectorias tales que den lugar impactos podría cuantificarse en el entorno de 1/200 (entre 1/150 y $1 / 250$ ). Este valor permite entender la inexistencia de problemas en los últimos 50 años.

Para el ámbito de las infraestructuras de ingeniería civil, se puede considerar un valor de 1/1000 como el riesgo aceptable de perdida de una vida. Este valor está basado en que el índice de fatalidades asociado a obras humanas no debería superar el riesgo de muerte natural de la franja de población más sana (niños de 10 a 14) que es de 1/1000. Además, este suele ser un nivel de consenso para limitar zonas de acceso voluntario (restricción de acceso de personal a la zona) y zonas uso público. Por todo ello, se considera que algunas casas bajo la ladera presentan un riesgo por desprendimientos por encima del aceptable para zonas de uso público. Por tanto, se recomendó proteger dichas edificaciones mediante la instalación de una barrera dinámica de $3 \mathrm{~m}$ de altura que retendría todos los bloques según los modelos de caída de bloques y capaz de asumir una energía de 500 kJ. Dicha barrera fue finalmente instalada en la zona.

La Figura 18 muestra la aplicación de la Tabla del RHRS al caso en cuestión. Obviamente esto no se puede aplicar directamente para el caso de afectación a viviendas, pero se presenta aquí a modo orientativo, considerando las viviendas equivalentes a la constante presencia de coches bajo el talud. Como se observa se obtiene un valor del RHRS en torno a 400 , considerando las edificaciones como coches que se encuentran siempre ocupando la carretera. Este valor estaría entre un talud de baja prioridad (300) y un talud que requiere acción inmediata (500).

De acuerdo con el enfoque propuesto por Mölk et al. (2008), las áreas de caída de rocas identificadas se clasifican puntuando parámetros análogos a los propuestos para el RHRS. No se presentan aquí por brevedad. De dichos parámetros se deriva el diagrama de la Figura 19. Como se puede ver, el caso estudiado presentaría antes y después del incendio y un nivel de riesgo inaceptable. Sin embargo, en el primer caso este nivel estaría más cerca de situaciones aceptables. En consecuencia, y luego de la aplicación de $R^{3} S^{2}$, se necesitarían medidas de mitigación en línea con otros enfoques presentados en este estudio.

Como se observa, estos métodos empíricos pueden resultar de gran ayuda en las primeras fases del análisis y sirven de comparación para los métodos más teóricos, típicamente más exactos, pero que dependen de muchos parámetros a veces difíciles de cuantificar de manera rigurosa. 
Tabla de estimación de la clasificación detallada del RHRS

Rockfall Hazard Rating System (Traducido de Pierson et al., 1990). Aplicación estimativaa la cantera sur del 'Monte do Castro'

Criterio de valoración y puntuación

\section{Categoría}

Altura del talud

Efectividad de la cuneta de recepción

Riesgo medio vehicular (AVR)

Porcentaje de la visibilidad (SD) frente a la distancia de reacción (DSD)

Anchura de la calzada incluido el arcén

Caso 1

Condición

Caso 1

friccion te

junts

\begin{tabular}{|c|c|c|c|}
\hline 3 Puntos & 9 Puntos & 27 Puntos & 81 Puntc \\
\hline $\begin{array}{l}25 \text { pies } \\
(7.6 \mathrm{~m})\end{array}$ & $\begin{array}{l}50 \text { pies } \\
(15.2 \mathrm{~m})\end{array}$ & $\begin{array}{l}75 \text { pies } \\
(22.9 \mathrm{~m})\end{array}$ & $\begin{array}{l}100 \text { pies } \\
(30.5 \mathrm{~m})\end{array}$ \\
\hline Bueno & Moderado & Limitado & Nula \\
\hline $\begin{array}{l}25 \% \text { del } \\
\text { tiempo }\end{array}$ & $\begin{array}{l}50 \% \text { del } \\
\text { tiempo }\end{array}$ & $\begin{array}{l}75 \% \text { del } \\
\text { tiempo }\end{array}$ & $\begin{array}{c}100 \% \text { del } \\
\text { tiempo }\end{array}$ \\
\hline $\begin{array}{l}\text { Suficiente } \\
\text { visibilidad } \\
\text { (100\% DSD) }\end{array}$ & $\begin{array}{l}\text { Moderada } \\
\text { visibilidad } \\
\text { (80\% DSD) }\end{array}$ & $\begin{array}{l}\text { Visibilidad } \\
\text { limitada } \\
\text { (60\% DSD) }\end{array}$ & $\begin{array}{c}\text { Visibilidad } \\
\text { muy } \\
\text { limitado } \\
\text { (40\% 050) }\end{array}$ \\
\hline $\begin{array}{l}44 \text { pies } \\
(13.4 \mathrm{~m})\end{array}$ & $\begin{array}{l}36 \text { pies } \\
(11.0 \mathrm{~m})\end{array}$ & $\begin{array}{l}28 \text { pies } \\
(8.5 \mathrm{~m})\end{array}$ & $\begin{array}{l}20 \text { pies } \\
(6.1 \mathrm{~m})\end{array}$ \\
\hline $\begin{array}{c}\text { Juntas } \\
\text { discontinuas } \\
\text { con } \\
\text { orientación } \\
\text { favorable }\end{array}$ & $\begin{array}{l}\text { Juntas } \\
\text { discontinuas } \\
\text { con } \\
\text { orientación } \\
\text { variable }\end{array}$ & $\begin{array}{l}\text { Juntas } \\
\text { discontinuas } \\
\text { con } \\
\text { orientación } \\
\text { adversa }\end{array}$ & $\begin{array}{c}\text { Juntas } \\
\text { continuas } \\
\text { con } \\
\text { orientación } \\
\text { adversa }\end{array}$ \\
\hline $\begin{array}{l}\text { Rugosae } \\
\text { irregular }\end{array}$ & Ondulada & Plans & Conre \\
\hline
\end{tabular}

Geologia

Clima y presencia de agua en el talud

Hlstoria de caida de bloques

\section{Diferencias en \\ caracteristicas \\ erosivas}

Caso 2

Diferencias en la velocidad de erosion

\section{Tamaño del bloque individual}

Volumen de rocas a caer por evento
Figura 18. Tabla de estimación de la clasificación del RHRS (Rockfall Hazard Rating System), al Monte do Castro, salvando la excepción de la no presencia de vehículos, para la que no está diseñado el sistema.

Figure 18. Rockfall Hazard Rating System estimation table adapted to the occurrence of buildings below the slope.

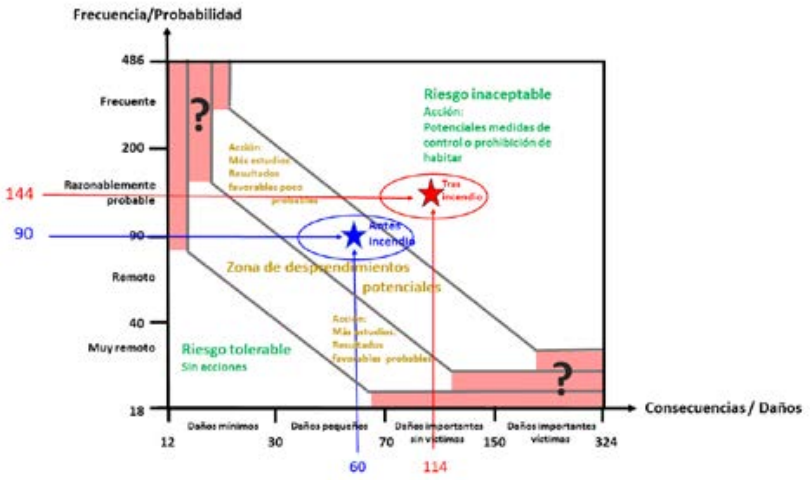

Figura 19. Diagrama de frecuencia / consecuencia propuesto por Mölk et al. (2018) para el caso de estudio, considerándolo antes y después del incendio.

Figure 19. Frequency / consequence diagram proposed by Mölk et al. (2018) for the case study, considered before and after the fire.

\section{Estabilidad de bolos sueltos}

Como ya se adelantaba en la sección 2, los bolos graníticos representan una de las formas de relieve positivo más características en terrenos de dicha litología que pueden dar lugar a problemas de estabilidad. Aunque muchos de estos bolos graníticos reposan en lugares donde difícilmente pueden representar un peligro para personas o bienes, algunos de ellos se localizan en laderas sobre las cuales podrían desprenderse fruto de un descalce progresivo de la base o debido a la ocurrencia de un sismo. Los mecanismos clásicos de inestabilidad en taludes, principalmente el deslizamiento y el vuelco de bloques o conjuntos de bloques, serán también los que afecten a la estabilidad de los bolos graníticos. Sin embargo, se ha de hacer hincapié en algunas particularidades asociadas a su geometría irregular, tanto en la caracterización como el cálculo de estabilidad de bolos frente a estos mecanismos.

\section{Descripción típica de los fenómenos a estudiar y me- canismos de inestabilidad}

En algunas ocasiones, los bolos graníticos se pueden presentar, ya sea aislados o agrupados, en una posición cercana al equilibrio límite. Este estado límite puede implicar un peligro, en cierta manera incrementado debido al tamaño alcanzado por alguno de estos bolos (véase, por ejemplo, el Leviathan Boulder localizado en Victoria, Australia y descrito en Twidale and Vidal-Romaní (2005), con una longitud aproximada de $33 \mathrm{~m}$ o los mostrados en la Figura 3), pero esencialmente fruto de la posición de estas estructuras en laderas que pueden presentar una inclinación relevante, con el consiguiente riesgo de desprendimiento.

Conceptualmente, un bolo localizado en una ladera se podría entender como un problema de un bloque en un plano inclinado, cuyos mecanismos de inestabilidad principales serían el deslizamiento a lo largo del contacto bloque-plano o el vuelco alrededor de una de sus aristas. Sin embargo, se ha observado que estos mecanismos de inestabilidad podrían verse afectados por algunos factores asociados a la naturaleza de los bolos. Por un lado, el redondeo de las aristas debido a la meteorización, afecta a la estabilidad frente al vuelco. Este es un efecto que ya ha sido estudiado por algunos de los autores de este artículo para el caso de bloques esbeltos y conjuntos de bloques en taludes (Alejano et al. 2015, 2018). Por otro lado, estos bolos presentan una forma irregular, hecho que afecta a la distribución de la masa y, por tanto, a la posición del centro de gravedad. Esto hace que el estudio de la estabilidad frente al vuelco sea más complejo que para el caso de bloques regulares que presentan planos de simetría claros. Además, el tipo de contacto entre el bolo y el plano sobre el que reposa influye de manera relevante en la estabilidad de este tipo de 
estructuras geomorfológicas. Por tanto, todas estas particularidades suscitan un estudio más pormenorizado, tanto de las técnicas de caracterización geomecánica y geométrica como de aquellas empleadas en el análisis de estabilidad de los bolos, las cuales se describen a continuación.

\section{Técnicas de caracterización}

El estudio de estabilidad de un bolo granítico requerirá, por un lado, de una caracterización geométrica (ángulo y dirección de buzamiento) y geomecánica de la discontinuidad sobre la que reposa el bolo. Además, también será necesario definir geométricamente la propia estructura para poder realizar un cálculo del volumen y de la masa y, consecuentemente, de las tensiones ejercidas por el bolo en el plano de contacto, así como el posicionamiento del centro de gravedad del mismo. Los resultados de esta caracterización servirán como parámetros de entrada del criterio de estabilidad empleado para la estimación analítica de la resistencia tangencial disponible. Además, se emplearán a la hora de calcular la estabilidad frente al mecanismo de vuelco.

Una caracterización geométrica y geomecánica de la discontinuidad sobre la que reposa el bolo se puede llevar a cabo, en su versión más simple, mediante un equipo básico de geología de campo. Esto implica, de acuerdo con los criterios de evaluación de la resistencia al corte más comúnmente empleados (véase, por ejemplo, Barton y Choubey (1977); Barton y Bandis (1982); Zhao (1997)) la estimación de parámetros como el ángulo de fricción residual $\left(\phi_{r}\right)$, la rugosidad $(J R C)$ o la resistencia a la compresión de la junta (JCS), además de la medición del ángulo y dirección de buzamiento de la propia discontinuidad o el nivel de acoplamiento o encaje de ambas caras del contacto (JMC).

Se debe destacar que, desde principios del siglo $\mathrm{XXI}$, ha habido un gran desarrollo de las técnicas de adquisición remota de datos como son el LiDAR ( $L i-$ ght Detection and Ranging), el DInSAR (Differential $S A R$ Interferometry) y la fotogrametría desde vehículo aéreo no tripulado (dron). Estos métodos se han ido aplicando consecuentemente en la adquisición de datos para la caracterización de taludes rocosos, pero, sobre todo, en la extracción semi-automática de parámetros 3D del macizo rocoso a partir de las nubes de puntos obtenidas por medio de estas técnicas (p. ej. Riquelme et al. 2014, Jaboyedoff et al., 2007). Una de las características de estos métodos es que permiten obtener una gran cantidad de información (en forma de nubes de puntos georreferenciados) de la estructura del macizo rocoso a estudiar en relativamente poco tiempo, de manera apenas sesgada y de zonas donde el acceso puede resultar complicado. Haciendo uso de estas técnicas es, por tanto, posible obtener, mediante una adecuada gestión de estas nubes de puntos, los parámetros geométricos (ángulo y la dirección de buzamiento) de la discontinuidad sobre la que reposa el bolo de una manera muy precisa.

Para la caracterización del propio bolo en sí, es necesaria la estimación de dos parámetros básicos: el área de contacto entre el bolo y la discontinuidad de reposo, así como el volumen y forma del mismo.

La medición del área de contacto se puede realizar in situ mediante el empleo de medios manuales, como una cinta métrica, para realizar una aproximación poligonal del área de contacto (véase, por ejemplo, Alejano et al. (2008), donde se estudia la estabilidad del Penedo da Sobreira («Roca del Alcornoque»)) o un cordel o hilo inextensible que permita obtener un perímetro a partir del cual se puede estimar un área (por ejemplo, considerando contacto elíptico o circular). Sin embargo, hoy en día se puede recurrir a software específico para el tratamiento de nubes de puntos, como puede ser el software de distribución gratuita CloudCompare (Girardeau-Monteaut, 2018) y a herramientas de diseño asistido por computador (CAD) para obtener, a partir de un levantamiento topográfico en 3D de la estructura (por ejemplo, mediante láser escáner terrestre (TLS) y fotogrametría aérea), una estimación del área de contacto muy precisa (Figura 20 (d)).

La estimación del volumen del bolo se puede llevar a cabo, de una manera muy precisa, a partir de una nube de puntos 3D obtenida mediante topografía avanzada (Armesto et al. 2009; Pérez-Rey et al. 2019b) (Figura 20). Es necesario puntualizar que la estructura debe quedar definida lo más completamente posible para poder generar la malla a partir de la cual se estimará el volumen, algo que puede requerir el uso combinado de fotogrametría aérea y láser escáner terrestre (TLS) para recoger información de todas las partes del bolo, en especial de la zona de contacto y de aquellas partes no accesibles (tíicamente la zona superior) debido al tamaño alcanzado por algunos bolos.

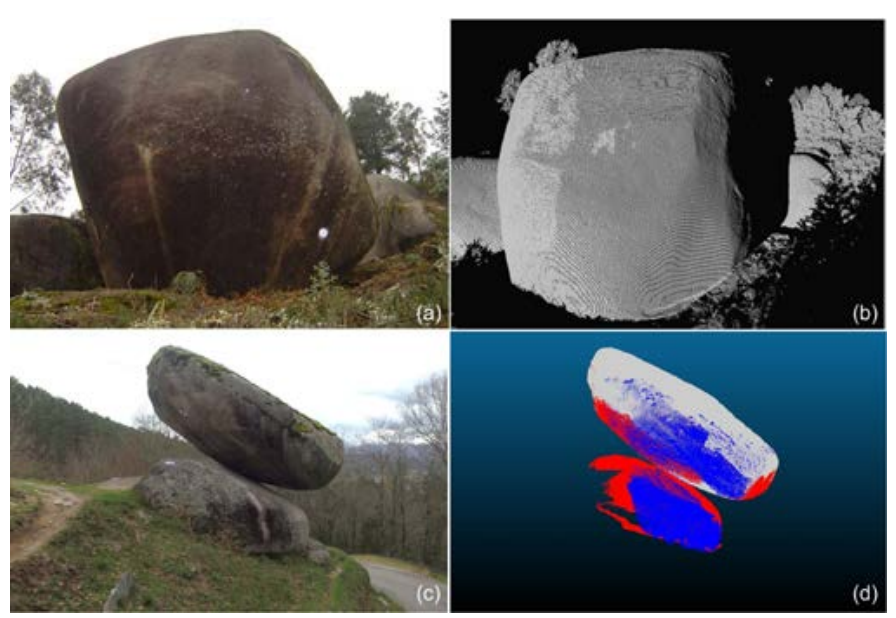

Figura 20. Fotografías del Penedo da Sobreira (a) y de la Pena do Equilibrio (c) y vistas de las nubes de puntos correspondientes obtenidas mediante TLS (b) y mediante combinación de TLS y fotogrametría mediante dron (d).

Figure 20. Photographs of the 'Penedo da Sobreira' (a) and the 'Pena do Equilibrio' (c) and views of the point clouds obtained by TLS (b) and by combination of TLS and photogrammetry by drone (d). 
Para la estimación del volumen del bolo en particular, habrá que aislar los puntos representativos del mismo del resto de la nube de puntos $3 D$, lo cual se puede llevar a cabo con un software específico de tratamiento de nubes de puntos en 3D. Una vez seleccionado este conjunto de puntos, se deberá generar una malla representativa de los mismos para poder estimar el volumen que encierra y que será una aproximación razonablemente exacta del volumen real del propio bolo.

Hay que tener en cuenta que no se dispondrá de información de la zona del contacto, la cual habrá que extrapolar en función de la geometría de la propia estructura. Este trabajo se puede realizar con algún software de procesado y edición de mallas triangulares en 3D (véase, por ejemplo, el software libre MeshLab (Cignoni et al. 2008)). Este tipo de software permite también posicionar el centro de gravedad del bolo objeto de estudio, en un sistema de coordenadas 3D local $(x, y, z)$.

\section{Técnicas de Análisis}

El análisis de estabilidad de bolos graníticos se realizará a través del estudio del equilibrio límite frente a dos mecanismos básicos de inestabilidad, como son el deslizamiento y el vuelco. Ambos enfoques se llevarán a cabo mediante el uso de un factor o coeficiente de seguridad (CS), el cual relaciona los esfuerzos disponibles, frente a los ejercidos por la propia estructura en el contacto (para el caso del deslizamiento) y los momentos que tienden a estabilizar el bolo frente a los que tienden a volcarlo (para el caso del vuelco).

A continuación, se presentan las ecuaciones generales que permiten obtener el coeficiente de seguridad estático frente a deslizamiento (Ecuación 5.1) y frente a vuelco (Ecuación 5.2). Estas ecuaciones también se pueden aplicar, incluyendo convenientemente un coeficiente de aceleración sísmica $\alpha$, para el caso de un análisis pseudo-estático.

donde:

$$
C S_{\text {deslizamiento }}=\frac{\tan \phi_{b}}{\tan \beta}
$$

$\phi_{b}=$ ángulo de fricción básico de la discontinuidad (según Alejano et al. 2019)

$\beta=$ ángulo de buzamiento de la discontinuidad

$$
C S_{\text {vuelco }}=\frac{\sum M_{\text {estabilizadores }}}{\sum M_{\text {volcadores }}}
$$

donde:

$M_{\text {estabilizadores }}=$ momentos creados por aquellas fuerzas que tienden a estabilizar el bolo

$M_{\text {volcadores }}=$ momentos creados por aquellas fuerzas que tienden a volcar el bolo

Como se ha adelantado anteriormente, se deberá tener en cuenta el redondeo que ha sufrido el bolo debido a la meteorización, pues influirá a la hora de estimar su estabilidad frente a vuelco.

A manera de ejemplo se pueden utilizar ábacos como el propuesto en la Figura 21 que dan una idea de la influencia conjunta del redondeo y la esbeltez en la estabilidad de bolos. Como se puede observar, los bolos con dimensiones sub-verticales mayores (mayor esbeltez) son más propensos al vuelco que aquellos más chatos. Si en la Figura 21 se toma un valor determinado del factor de redondeo (por ejemplo, $\rho=$ $0.5)$ se puede observar que para las esbelteces mayores $(\mathrm{L} / \mathrm{H}=0.5)$ la inestabilidad frente a vuelco aparece en torno a un ángulo de buzamiento menor de $15^{\circ}$, mientras que, para el mismo factor de redondeo y un bolo menos esbelto, la inestabilidad frente al vuelco aparece en torno a un buzamiento de la discontinuidad sobre la que reposa de unos $53^{\circ}$.

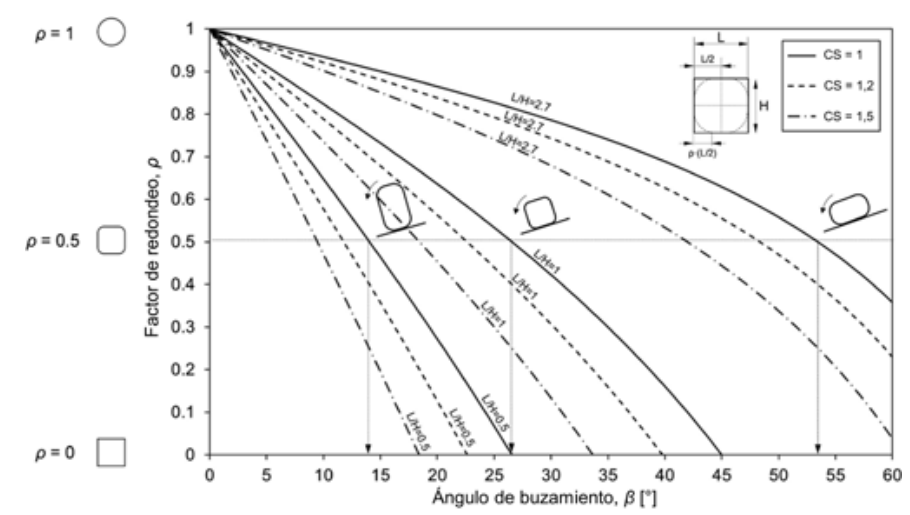

Figura 21. Ábaco para estimar la estabilidad frente a vuelco (2D) de bolos con diferentes estados de redondeo y esbeltez, para diferentes niveles del coeficiente de seguridad (CS).

Figure 21. Chart to estimate stability against toppling (2D) of boulders with different levels of corner roundness and shape slenderness, for different levels of the safety coefficient (CS).

Además, también se ha de tener en cuenta la posición del centro de gravedad del bolo a la hora de realizar los cálculos de estabilidad. Para el caso de estructuras regulares y simétricas, es posible situar fácilmente este punto en su centro y en sus planos de simetría (como, por ejemplo, para el caso de un prisma de base rectangular). Sin embargo, para bolos reales con geometría irregular, la localización del centro de gravedad no es tan evidente y hay que obtenerla por medio de algún algoritmo. Es por ello por lo que se propone el uso de un software tenga implementada esta herramienta, como por ejemplo MeshLab (Cignoni et al. 2008), para el procesado y gestión de una nube de puntos 3D representativa del bolo y una correcta estimación de su posición.

Tras realizar algunos experimentos con modelos físicos en laboratorio, se observaron (Pérez-Rey et al. 2019b) dos particularidades que se han de tener en cuenta a la hora de analizar la estabilidad frente a vuelco de bolos irregulares: la primera es que un posicionamiento del centro de gravedad fuera del plano 
vertical que contiene a la línea de máxima pendiente reducirá el ángulo crítico de vuelco del bolo y, por ende, el coeficiente de seguridad. La segunda es que el bolo tenderá a volcar en una dirección marcada por la posición de ese centro de gravedad, y que difiere de la marcada por la línea de máxima pendiente.

\section{Ejemplo}

Como caso de estudio se ha seleccionado un bolo granítico de grandes dimensiones situado en el entorno de Ponteareas y cuya estabilidad ha sido recientemente estudiada. Este bolo es denominado localmente Pena do Equilibrio por su posición en la ladera, que se muestra en la Figura 22(a). Un estudio sobre la estabilidad de este bolo con mayor información de detalle, se puede consultar en la bibliografía (Pérez-Rey et al. 2019b).

El bolo está formado por una granodiorita biotítico-anfibólica de grano fino a medio. La estructura presenta una longitud de unos $9 \mathrm{~m}$ y una altura de unos $3.7 \mathrm{~m}$ y reposa sobre otro bolo, embebido parcialmente en el macizo rocoso, también de grandes dimensiones. Otras características de la estructura, como se puede apreciar en las fotografías de la Figura 22 son su forma sub-elipsoidal, así como su posición con respecto a la carretera, con un buzamiento del plano de apoyo, $\beta=27^{\circ}$. Cabe además destacar la aparentemente pequeña área de contacto entre ambos bloques.

Para el estudio de la estabilidad de este bolo, se llevó a cabo primeramente una caracterización de la discontinuidad donde reposa, a partir de un reconocimiento en campo de parámetros geomecánicos, basado en el criterio de resistencia al corte de discon-

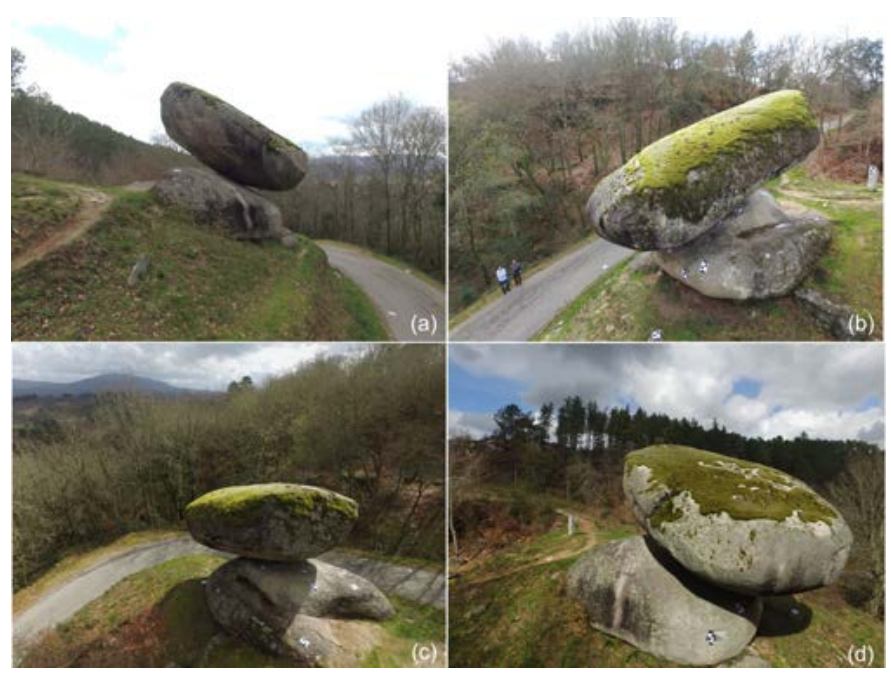

Figura 22. Diferentes vistas de la Pena do Equilibrio tomadas desde un dron Phantom 3. (a) vista desde el Oeste; (b) vista desde el Este; (c) vista desde el Norte; (d) vista desde el Sur.

Figure 22. Different views of the Pena do Equilibrio taken from a Phantom drone 3. (a) Seen from the west; (b) seen from the east; (c) seen from the north; (d) seen from the south. tinuidades propuesto por Zhao (1997), basado en las ecuaciones de Barton y sus colaboradores (Barton y Choubey, 1977; Barton y Bandis, 1982).

Así, en el entorno del bolo se midieron varios perfiles de rugosidad para la obtención del coeficiente de rugosidad de la junta $(J R C)$ y se realizaron medidas del número de rebotes del martillo Schmidt sobre varias zonas de la discontinuidad para la obtención de la resistencia a la compresión de la junta o (JCS). Para tener en cuenta el efecto de la meteorización sobre el contacto y como se ha podido observar in situ, se ha propuesto un valor representativo del acoplamiento de las caras del contacto $(J M C)$ del orden de 0,3 . Esta toma de datos se completó con ensayos de densidad y de inclinación (o tilt-tests) para obtener el ángulo de fricción básico de la discontinuidad en laboratorio (Alejano et al., 2018b). En la Tabla 4 se resumen los parámetros geomecánicos más relevantes.

\begin{tabular}{ll}
\hline Parámctro & Valor \\
\hline $\mathrm{N}^{0}$ de rebotes del martillo Schmidt sobre la junta (r) & 46 \\
$\mathrm{~N}^{0}$ de rebotes del martillo Schmidt sobre roca fresca (R) & 52 \\
Coeficiente de rugosidad de la junta, JRC & 11 \\
Resistencia a la compresión de la junta, JC'S, basada en (r) & 112 \\
{$[\mathrm{MPa}]$} & \\
$\begin{array}{l}\text { Coeficiente de acoplamiento de los planos del contacto } \\
(J M C)\end{array}$ & 0.3 \\
Ángulo de fricción básico, $\phi_{b}\left[{ }^{\circ}\right]$ & 34 \\
Peso específico de la roca $\left[\mathrm{kN} / \mathrm{m}^{3}\right]$ & 25.7
\end{tabular}

Tabla 4. Parámetros geomecánicos básicos de la discontinuidad y de la roca.

Table 4. Basic geomechanical parameters of the discontinuity and rock.

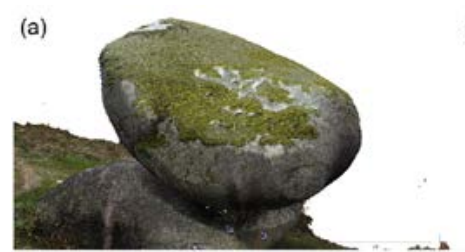

(b)
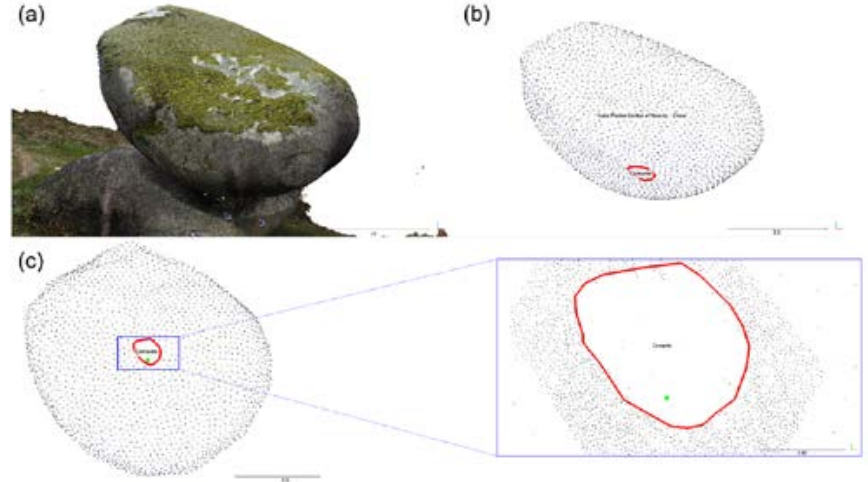

Figura 23. Reconstrucción en 3D de la Pena do Equilibrio; (b), (c): aislamiento del bolo para el cálculo del volumen; (d): extracción del área de contacto entre el bolo y la discontinuidad de apoyo (estos procesos fueron realizados con el software CloudCompare).

Figure 23. 3D reconstruction of the Pena do Equilibrio; (b), (c): isolation of the boulder for volume calculation purposes; (d): extraction of the contact area between the boulder and the basal discontinuity (these processes were carried out with the help of CloudCompare software). 
Asimismo, se realizó una estimación tanto de la geometría del bolo como del área de contacto y del plano que la contiene. Este proceso se llevó a cabo a partir de una reconstrucción en 3D de la estructura geológica, realizado a partir de fotogrametría aérea mediante dron, complementada con información topográfica proporcionada por distintos estacionamientos con un equipo de láser escáner terrestre (TLS). Así se obtuvo una nube de puntos 3D de alta precisión de la cual se extrajo la información correspondiente al bolo, para el cálculo del volumen y el posicionamiento del centro de gravedad, así como de las dimensiones del área de contacto. Este proceso se ilustra mediante la Figura 23 aunque se remite al lector a una publicación al respecto (Pérez-Rey et al. 2019b) para información más detallada.

De este análisis se estima un volumen, $W_{b}=142.22$ $\mathrm{m}^{3}$, un área de contacto de $A=0.62 \mathrm{~m}^{2}$, así como la localización exacta del centro de gravedad. Con el valor de las tensión normal y cortante calculada en el contacto y teniendo en cuenta el ángulo de fricción de pico obtenido mediante el criterio de resistencia al corte de Zhao (1997), se pueden estimar, desarrollando las ecuaciones 5.1 y 5.2 , tanto el valor del coeficiente de seguridad frente a deslizamiento como frente a vuelco. Para el caso de ocurrencia del máximo sismo esperado, y haciendo hincapié en la normativa española al respecto (MFOM, 2002), se tomó un valor de aceleración sísmica $\alpha=0.032$. Los coeficientes de seguridad obtenidos, para deslizamiento y vuelco sin sismo fueron $\mathrm{CS}_{\mathrm{d}}=1.31$ y $\mathrm{CS}_{\mathrm{v}}=1.20$, respectivamente. Si se incluye el efecto del sismo, los coeficientes de seguridad quedarían $\mathrm{CS}_{\mathrm{d}, \alpha=0.032}=1.21$ y $\mathrm{CS}_{\mathrm{v}, \alpha=0.032}=1.11$.

Se consideró también la posibilidad de ocurrencia de un sismo extraordinario, como el que tuvo epicentro en el margen sudoeste de Portugal, conocido como el terremoto de Lisboa (Baptista and Miranda, 2009). Una cuantificación aproximada de los efectos de este terremoto en el área de estudio del bolo fue realizada por Amaré-Tafalla et al. (2005), derivándose de este estudio una aceleración sísmica para esta situación en la zona del bolo, $\nabla=0.065$. Si se repiten los cálculos del coeficiente de seguridad de manera similar a la presentada anteriormente con este valor se obtendría, para deslizamiento, un $\mathrm{CS}_{\mathrm{d}, \alpha=0.065}=1.12$ y para vuelco, un $\mathrm{CS}_{\mathrm{v}, \alpha=0.065}=1.03$.

Del análisis de los coeficientes de seguridad, se puede determinar que la estabilidad del bolo está asegurada en las condiciones actuales, sin embargo, en caso de la improbable ocurrencia de un evento sísmico que provocase una aceleración sísmica del orden de la mostrada en el caso más desfavorable, la estabilidad del bolo se vería comprometida.

\section{Conclusiones}

Con base en la experiencia acumulada por los autores, en este artículo se presenta una revisión de los fenómenos de inestabilidad que se producen típica- mente en laderas naturales en terrenos graníticos. Uno de los fenómenos más relevantes que afecta a la estabilidad de este tipo de macizos rocosos es la meteorización, la cual, en parte, es el mecanismo a través del cual se originan los tres tipos principales de escenarios que se consideran en el presente estudio: laderas en jabre, campos de bolos y bolos aislados de geometría irregular. Dadas las particularidades inherentes a la formación y evolución de este tipo de estructuras graníticas, el estudio de estabilidad de cada caso requiere una adaptación de las metodologías clásicas de análisis en mecánica de rocas, que se ilustran en el presente artículo.

Así, para el caso de laderas en jabre, conviene acudir a métodos de caracterización sencillos y económicos, ya que este tipo de materiales es altamente variable tanto en su distribución espacial como en su comportamiento. Será relevante pues una buena caracterización geotécnica del propio jabre, además de tener un buen conocimiento de la geometría de la ladera y la presencia de agua. Los métodos de fajas suelen ser los más apropiados para la realización de cálculos en estos casos.

Para la gestión de la estabilidad y la evaluación del riesgo por desprendimientos en laderas graníticas formadas por bolos de tamaño mediano, la combinación de técnicas de topografía avanzadas (fotogrametría mediante dron) con el análisis geoestructural semi-automatizado sobre nubes de puntos 3D permite no sólo obtener un tamaño de bloque medio realista que sirva como entrada en los modelos computacionales de desprendimientos sino también cubrir un área de análisis extensa en un tiempo relativamente corto. Además, los autores recomiendan el uso de técnicas más teóricas con programas de estudio de trayectorias junto con metodologías empíricas de estimación de riesgo. En el caso práctico que se presenta, la aplicación de esta metodología ha permitido el diseño adecuado de un sistema de contención de potenciales desprendimientos (barrera dinámica) en el área de estudio.

Por último, para evaluar la estabilidad de grandes bolos aislados irregulares, además de emplear técnicas clásicas de caracterización de las discontinuidades sobre las que reposan estas estructuras, es crítico el conocimiento de un volumen lo más exacto posible del bolo, así como de la extensión del área del contacto y la posición de su centro de gravedad. También pues en este caso, las técnicas de topografía avanzada se erigen como las más adecuadas para la obtención de una nube de puntos en 3D representativa de la estructura. Este conjunto de datos se puede gestionar con software específico, permitiendo obtener una caracterización geométrica de la estructura muy exacta. Con esta información y la adecuada caracterización geotécnica, ha sido posible determinar el nivel de estabilidad de un bolo granítico frente al deslizamiento como al vuelco, tanto en condiciones estáticas como de ocurrencia de un sismo. 


\section{Referencias}

Agliardi, F. and Crosta, G.B. 2003. High resolution three-dimensional numerical modelling of rockfalls. International Journal of Rock Mechanics and Mining Sciences, 40:455-471.

Alejano, L.R., Carranza-Torres, C., Giani, G.P. and Arzúa, J. 2015. Study of the stability against toppling of rock blocks with rounded edges based on analytical and experimental approaches. Engineering Geology, 195:172-184.

Alejano, L.R., Muralha, J., Ulusay, R., Li, C.C., Pérez-Rey, I., Karakul, H., Chryssanthakis, P. and Aydan, O. 2018b. ISRM suggested method for determining the basic friction angle of planar rock surfaces by means of tilt tests. Rock Mechanics and Rock Engineering, 51(12), 3853-3859.

Alejano, L.R., Ordóñez, C., Armesto, J. and Rivas T. 2010. Assessment of the instability hazard of a granite boulder. Natural Hazards, 53(1):77-95.

Alejano, L.R., Pons, B. and Bastante, F.G., Alonso, E. and Stockhausen, H.W. 2007. Slope geometry design as a means for controlling rockfalls in quarries. International Journal of Rock Mechanics and Mining Sciences, 44: 903-921.

Alejano, L.R., Sánchez-Alonso, C., Pérez-Rey, I., Arzúa, J., Alonso, E., González, J., Beltramone, L. and Ferrero, A.M. 2018a. Block toppling stability in the case of rock blocks with rounded edges. Engineering Geology, 234:192-203.

Alejano, L.R., Stockhausen, H.W., Alonso, E., Bastante, F.G. and Ramírez-Oyanguren, P. 2008. ROFRAQ: A statistics-based empirical method for assessing accident risk from rockfalls in quarries. International Journal of Rock Mechanics and Mining Sciences, 45:1252-1272.

Amaré-Tafalla, M., Orche-García, E. and Puche-Riart, O. 2005 Efectos del terremoto de Lisboa de 1 de noviembre de 1755 en la antigua provincia de Tuy (Galicia) - The effects of Lisbon earthquake of 1 november, 1755 on the Ancient Province of Tuy. Cuadernos Dieciochistas, 6:117-152.

Armesto, J., Ordóñez, C., Alejano, L.R. and Arias, P. 2009 Terrestrial laser scanning used to determine the geometry of a granite boulder for stability analysis purposes. Geomorphology, 106(3):271-277.

Baptista, M.A. and Miranda, J.M. 2009. Revision of the Portuguese catalog of tsunamis. Natural Hazards and Earth System Sciences, 9(1):25-42.

Barton, N. and Bandis, S. 1982. Effects of Block Size on the Shear Behaviour of Jointed Rock. Proceedings of the $23^{\text {rd }}$ US Symposium on Rock Mechanics, Issues in Rock Mechanics. Berkeley, California, 739760.

Barton, N. and Choubey, V. 1977. The shear strength of rock joints in theory and practice. Rock Mechanics, 10(1):1-54.

Bishop, A. W. 1955. The use of the slip circle in the stability analysis of slopes. Geotechnique 5: 7-17.
Cignoni, P., Callieri, M., Corsini, M., Dellepiane, M., Ganovelli, F. and Ranzuglia, G. 2008. MeshLab: an open-source mesh processing tool. Eurographics Italian Chapter Conference 2008. The Eurographics Association, 129-136.

CONTROLS 2009. Testing equipment for the construction industry. General Catalogue. (7th Edition). CONTROLS S.p.a., Milano, Italy.

Dawson, E.M., Roth, W, H. and Drescher, A., 1999. Slope stability analysis by strength reduction. Geotechnique 49: 835-840.

Durgin P. Landslides and weathering of granitic rocks. 1977. In: Coates D, ed. Reviews in Engineering Geology: Landslides. Boulder, Colorado: The Geological Society of America; 1977:278.

GEO. 1988. Guide to rock and soil descriptions. GEOGUIDE 3. Geotechnical Engineering Office. Civil Engineering Department. Hong Kong Government.

Giani, G.P., Giacomini, A., Migliazza, M. and Segalini, A. 2004. Experimental and Theoretical Studies to Improve Rock Fall Analysis and Protection Work Design. Rock Mechanics and Rock Engineering, 37:369-389.

Girardeau-Montaut, D. 2018. CloudCompare, http:// www.cloudcompare.org/.

Hamrol, A. 1961. A quantitative classification of the weathering and weatherability of rocks. In Proceedings of 5th Int. Conf.on Soil Mechanics and Foundation Eng. (Vol. 2) Paris, pp. 771-774.

Hencher, S.R. 2012. Practical Engineering Geology. CRC Press, $448 \mathrm{pp}$.

Hoek, E. and Bray, J. 1974. Rock Slope Engineering. Chapman \& Hall, 309 pp.

Hunt, R. E. 1984. Geotechnical Engineering Investigation Manual. McGraw-Hill. New York, 951 pp.

letto, F., Perri, F., Cella, F. 2018. Weathering characterization for landslides modeling in granitoid rock masses of the Capo Vaticano promontory (Calabria, Italy). Landslides, 15:43-62.

ITASCA. 2012. FLAC (Fast Lagrangian Analysis of Continua). Version 6.0. Itasca Consulting Group Inc., Minneapolis, Minnesota, EEUU.

ITGE, 1987. (Ayala, Andreu, Fe, Ferrer, De Simón, Fernandez, Olalla, Gómez, Sampedro y Cienfuegos). Manual de Ingeniería de taludes. ITGE, Madrid.

Jaboyedoff, M., Metzger, R., Oppikofer, T., Couture, R., Derron, M., Locat, J. and Turmel, D., 2007. New insight techniques to analyze rock-slope relief using DEM and 3D-imaging cloud points: COLTOP-3D software. Rock Mechanics. Meeting Society $₫ s$ Challenges and Demands. 1st Canada-US Rock Mechanics Symposium, Vancouver, Canada, p. 31.

Janbu, N. 1954. Application of composite slip circles for stability analysis. European conference on stability of earth slopes. 3:43-49. Estocolmo, Suecia.

Jiménez-Salas, J. A. and Justo-Alpañes, J. L. 1975. Geotecnia y Cimientos I. Caracterización de los Suelos y las Rocas. Editorial Rueda. Madrid. 470 pp.

Linton, D.L. 1955. The Problem ofTors. The Geographical Journal 121:470-487 
MFOM (Ministerio de Fomento). 2002. Real Decreto $997 / 2002$, de 27 de septiembre, por el que se aprueba la norma de construcción sismorresistente: parte general y edificación (NCSR-02). Boletín Oficial del Estado (BOE), 244:35898-35967.

Migoń, P. 2006. Geomorphological Landscapes of the World: 2. Granite Landscapes of the World. Oxford University Press, 375 pp.

Mölk, M., Poisel, R., Weilbold, J. and Angerer, H. 2008. Rockfall rating systems: is there a comprehensive method for hazard zoning in populated areas? $11^{\text {th }}$ Interpraevent Congress. Dornbirn, 2:207-218.

Moye, D.G. 1955. Engineering geology for the Snowy Mountains Scheme. Journal of the Institution of Engineers, Australia. 27:281-299.

NAVFAC. 1971. Design Manual DM-7: Soil mechanics foundations and earth structures. Naval Facilities Engineering Command, Washington, USA.

Ollier, C. 1975. Weathering. Longman, London, 304 pp.

Ollier, C.D. 1971. Causes of spheroidal weathering. Earth-Science Reviews. 7(3):127-141.

Palmer, J., Neilson, R.A. 1962. The origin of granite tors on Dartmoor, Devonshire. Proceedings of the Yorkshire Geological Society 33:315-340.

Pérez-Rey I, Riquelme A, González-deSantos LM, Estévez-Ventosa X, Tomás R, Alejano LR. 2019a. A multi-approach rockfall hazard assessment on a weathered-granite natural rock slope. Landslides. (Accepted for publication) doi: 10.1007/s10346-019-01208-5

Pérez-Rey, I., Alejano, L.R., Riquelme, A., González-deSantos, L. 2019b. Failure mechanisms and stability analyses of granitic boulders focusing a case study in Galicia (Spain). International Journal of Rock Mechanics and Mining Sciences, 19 (2019):58-71.

Pierson, L., Davis, S. and van Vickle, R. 1990. Rockfall Hazard Rating System implementation manual.
Federal Highway Administration report FHWA-OREG-90-01.

Riquelme, A., Abellán, A., Tomás, R. and Jaboyedoff, M. 2014. A new approach for semi-automatic rock mass joints recognition from 3D point clouds. Computers and Geosciences, 68:38-52. doi: https:// doi.org/10.1016/j.cageo.2014.03.014

RocScience 2016. SLIDE. User's Manual. Version 7.0. Rocscience, Inc., Toronto.

RocScience 2017. RocFall 6.0. User's Manual. Rocscience, Inc., Toronto.

RocScience. 2019. RS2 Version 2019 10.006. Finite Element Analysis. Rocscience, Inc., Toronto.

Sugawara, J., Yue, J.Q., Tham, L.G., Law, K.T. and Lee, C.F. 2003. Weathered rock characterization using drilling parameters. Canadian Goetechnical Journal, 40(3): 661-668.

Taboada, J., Alejano, L.R., García-Bastante, F. and Ordóñez, C. 2005. Explotación total de una cantera de granito ornamental (Total exploitation of an ornamental granite quarry). Materiales de Construcción, 42(4): 481-507.

Twidale, C. and Vidal-Romaní, J. 2005. Landforms and Geology of Granite Terrains. CRC Press.

Varnes, D. J. 1978. Slope movement types and processes. In: Special Report 176: Landslides: Analysis and Control (Eds: Schuster, R. L. \& Krizek, R. J.).

Vidal-Romaní J. 1989. Granite geomorphology in Galicia (NW Spain). Cad do Lab Xeolóxico Laxe Rev Xeol galega e do Hercínico Penins. 13: 89-163.

Wyllie, D. and Mah, C. 2004. Rock Slope Engineering. 4th ed. CRC Press (Taylor and Francis Group), 458 pp.

Zhao, J. 1997. Joint surface matching and shear strength. Part B: JRC-JMC shear strength criterion. International Journal of Rock Mechanics and Mining Sciences \& Geomechanics Abstracts, 34(2):179-185.
Recibido: julio 2020

Revisado: diciembre 2020

Aceptado: enero 2021

Publicado: diciembre 2021 